San Jose State University

SJSU ScholarWorks

Master's Theses

Master's Theses and Graduate Research

1997

\title{
Chromatographic quantification of elaidic acid in lard and Mexican dishes prepared with lard
}

Ana Gabriela Boardman

San Jose State University

Follow this and additional works at: https://scholarworks.sjsu.edu/etd_theses

\section{Recommended Citation}

Boardman, Ana Gabriela, "Chromatographic quantification of elaidic acid in lard and Mexican dishes prepared with lard" (1997). Master's Theses. 1423.

DOI: https://doi.org/10.31979/etd.ec8r-pkja

https://scholarworks.sjsu.edu/etd_theses/1423

This Thesis is brought to you for free and open access by the Master's Theses and Graduate Research at SJSU ScholarWorks. It has been accepted for inclusion in Master's Theses by an authorized administrator of SJSU ScholarWorks. For more information, please contact scholarworks@sjsu.edu. 


\section{INFORMATION TO USERS}

This manuscript has been reproduced from the microfilm master. UMI films the text directly from the original or copy submitted. Thus, some thesis and dissertation copies are in typewriter face, while others may be from any type of computer printer.

The quality of this reproduction is dependent upon the quality of the copy submitted. Broken or indistinct print, colored or poor quality illustrations and photographs, print bleedthrough, substandard margins, and improper alignment can adversely affect reproduction.

In the unlikely event that the author did not send UMI a complete manuscript and there are missing pages, these will be noted. Also, if unauthorized copyright material had to be removed, a note will indicate the deletion.

Oversize materials (e.g., maps, drawings, charts) are reproduced by sectioning the original, beginning at the upper left-hand comer and continuing from left to right in equal sections with small overlaps. Each original is also photographed in one exposure and is included in reduced form at the back of the book.

Photographs included in the original manuscript have been reproduced xerographically in this copy. Higher quality 6" $\times 9$ " black and white photographic prints are available for any photographs or illustrations appearing in this copy for an additional charge. Contact UMI directly to order.

\section{UMI}

A Bell \& Howell Information Company 



\title{
CHROMATOGRAPHIC QUANTIFICATION OF ELAIDIC ACID IN LARD AND MEXICAN DISHES PREPARED WITH LARD
}

\author{
A Thesis \\ Presented to \\ The Faculty of the Department of Nutrition and Food Science \\ San Jose State University
}

In Partial Fulfillment

of the Requirements for the Degree

Master of Science

by

Ana Gabriela Boardman

May 1997 
UMI Number: 1384672

UMI Microform 1384672

Copyright 1997, by UMI Company. All rights reserved.

This microform edition is protected against unauthorized copying under Title 17, United States Code.

\section{UMI \\ 300 North Zeeb Road \\ Ann Arbor, MI 48103}


APPROVED FOR THE DEPARTMENT OF NUTRITION AND FOOD SCIENCE

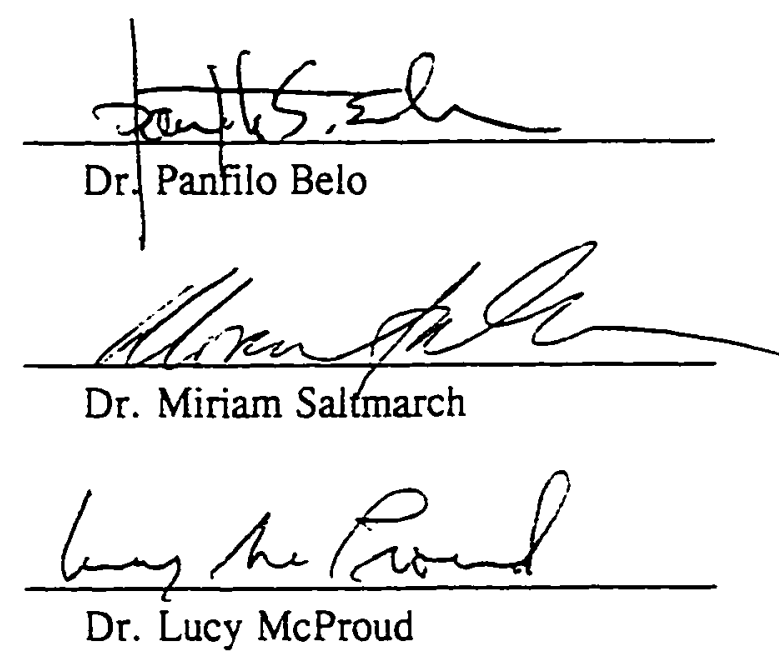

APPROVED FOR THE UNIVERSITY

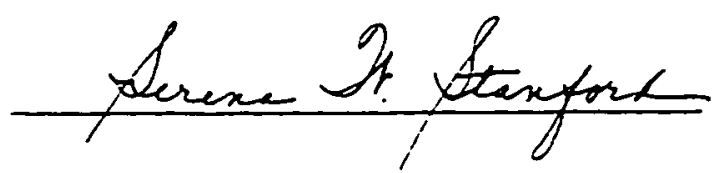


(C)

Ana Gabriela Boardman

ALL RIGHTS RESERVED 


\section{ABSTRACT \\ CHROMATOGRAPHIC QUANTIFICATION OF ELAIDIC \\ ACID IN LARD AND MEXICAN DISHES PREPARED WITH LARD}

by Ana Gabriela Boardman

Non hydrogenated lard samples obtained from a local Mexican grocery store, refried beans and beef tamale samples obtained from Bay area grocery stores were analyzed for total trans-9-octadecenoic (elaidic acid) composition. High performance glass capillary gas liquid chromatography on a $30 \mathrm{~m} \mathrm{5 \%}$ crosslinked $\mathrm{Ph}$ Me silicone column was employed in the separation and quantification of the cis- and transoctadecenoic fatty acids. Under operating conditions employed in this study, methyl esters of elaidic acid were separated from oleic acid without any other complementary technique. Total elaidic acid accounted for $0.02 \%, 0.23 \%$, and $0.506 \%$ of the total fatty acids present in lard, refried beans and beef tamale samples, respectively. Based on these values, the degree of isomerization (elaidic acid content relative to oleic acid content) was estimated to be $0.483 \mathrm{mg} / \mathrm{g}$ in lard, $3792 \mathrm{mg} / \mathrm{g}$ in refried beans, and $18.43 \mathrm{mg} / \mathrm{g}$ in beef tamale. On a wet basis, the total elaidic acid contents of lard, refried beans and beef tamale were $0.1857 \mathrm{mg} / \mathrm{g}, 0.0215 \mathrm{mg} / \mathrm{g}$ and $0.5869 \mathrm{mg} / \mathrm{g}$, respectively. The estimated intake of elaidic acid per serving per day was $82.7 \mathrm{mg}$ for beef tamale and $2.7 \mathrm{mg}$ for refried beans. 


\section{ACKNOWLEDGMENTS}

I would like to thank my graduate advisor, Dr. Panfilo Belo, for sharing his knowledge with me throughout my studies at San Jose State University. This research could not have been possible had it not been for the time, patience, faith, and encouragement Dr. Belo has invested in me over the past year. I would also like to thank Dr. Miriam Saltmarch for her support and guidance throughout my graduate studies at this university. I thank Dr. Lucy McProud for her guidance and assistance with manuscript organization. I would like to thank my family and friends for their unconditional support, throughout the course of my studies in the United States. 


\section{PREFACE}

The following is a publication style thesis. The second chapter is written in journal format and will be submitted to the Journal of The American Oil Chemists' Society.

Chapter I and III are written according to guidelines outlined in the Publication Mamial of the American Psychological Association, 4th edition, 1994. 


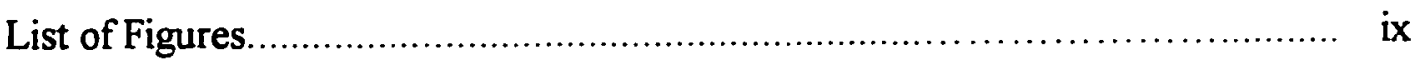

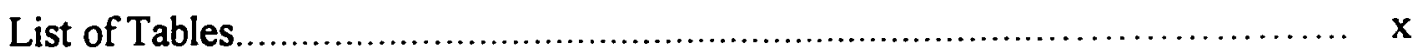

\section{CHAPTER}

1 INTRODUCTION AND REVIEW OF LITERATURE .................. 1

Introduction.............................................................

Objectives ................................................................. 4

Significance of the Study..................................... 4

Review of Literature.............................................. 5

Fats and oils............................................... 5

Biological Effects of Trans fatty acids............. 12

Mexican Food ................................................ 14

Lard ........................................................ 16

Chromatography .......................................... 18

Columns............................................ 20

Stationary phase..................................... 21

Detector ........................................... 22

Chromatographic Applications in Food Analysis... 23

Extraction and Transformation of the Fat

Sample for Chromatographic Analysis................ 24

Extraction...................................... 24

Transformation............................... 26

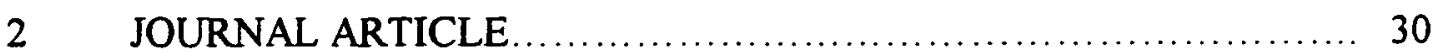

Authors Title Page............................................... 31

Abstract............................................................... 32

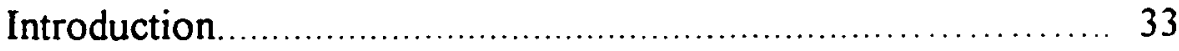


Materials and Methods........................................... 36

Chemicals................................................. 36

Samples................................................... 36

Sample Preparation........................................... 36

Lipid Extraction............................................ 36

Preparation of Free Fatty Acids............................. 37

Methylation ............................................... 37

Gas Liquid Chromatography............................... 37

Results and Discussion..................................... 39

Sample Preparation ................................. 39

Lipid extraction.................................... 39

Preparation of free fatty acids....................... 40

Methylation ........................................ 40

Gas Liquid Chromatography........................ 40

Acknowledgments.................................. 48

Literature Cited .................................... 48

3 SUMMARY AND RECOMMENDATIONS

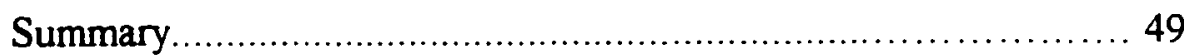

Recommendations............................................... 50

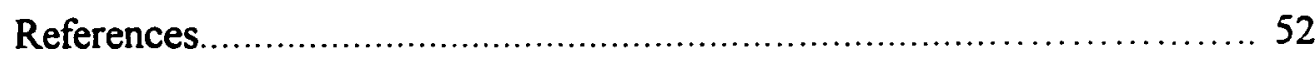




\section{List of Figures}

Figure

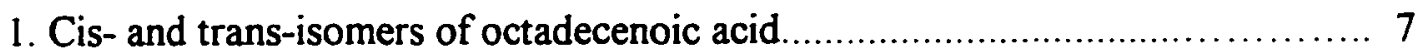

2. Possible conformations of octadecenoic acid isomers.......................... 10

3. Chromatographer oven temperature programming ............................. 38

4. Typical chromatographic separation of methyl esters of fatty acids from a pure mixture of oleic acid and elaidic acid.

5. Gas chromatographic separation of methyl ester of fatty acids from a lard sample.

6. Gas chromatographic separation of methyl esters of fatty acids from a beef tamale sample. 46

7. Gas chromatographic separation of methyl esters of fatty acids from a refried beans sample 47 


\section{List of Tables}

$\begin{array}{lll}\text { Table Page } & \text { Pag }\end{array}$

1. Physicochemical Properties of 9-Cis- and 9-Trans-octadecenoic Fatty

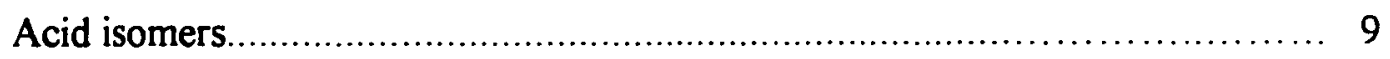

2. Trans Fatty Acid Content of Selected Food Items.............................. 11

3. Fatty Acids' Composition of Partially Hydrogenated Lard........................ 18

4. Moisture, fat, oleic and elaidic acid content of lard, refried beans and beef

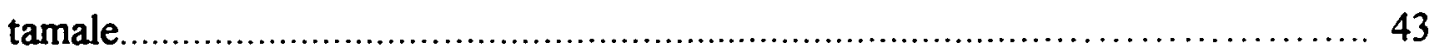




\section{CHAPTER 1}

\section{INTRODUCTION AND REVIEW OF LITERATURE}

\section{Introduction}

The importance of the effects of trans-fatty acids on human health has been the subject of international studies. Prior to 1990, U.S. and British studies had reported no adverse effects to human health. More recently however, trans fatty acids have been implicated in the development of arteriosclerosis and unfavorable lipoprotein profiles and increased morbidity and mortality from coronary heart disease (Karin \& Sacks, 1995; Salter, 1995; Stender, et al. 1995). Based on their findings from the chemistry, formation, metabolism, and assays of the trans-fatty acids consumed in Denmark, the Danish Nutrition Council recommended gradual reduction of trans-fat content of all Danish margarines to $5 \%$ or less (Stender, et al., 1995). In the EURAMIC study involving eight European countries and Israel, the authors concluded that there was considerable difference between countries in dietary intake of trans-fatty acids but no evidence of major effect of these isomers on myocardial infarction risk (Aro, et al., 1995). The authors indicated further that trans' isomers may have a significant impact on myocardial infarction risk in populations with high intake. Willet and Ascherio (1994) on the other hand believe that the combined results of metabolic and epidemiological studies strongly show that trans-fatty acid intake is causally related to cardiovascular heart disease and argue that because nearly everyone in the U.S. consumes partially hydrogenated fats, federal regulations should require listing of trans' isomers content on food labels.

Trans' FAs isomers are the result of the conversion, biohydrogenation or industrial hydrogenation, of the naturally occurring cis polyunsaturated 18-carbon fatty acids into a variety of isomers of oleic and linoleic acid (Enig, et al., 1990). Unsaturated fatty acids have two possible geometric isomer configurations: Cis and trans. The prefix cis 
indicates that the hydrogen atoms are on the same side of the double bond, and the prefix trans indicates that the hydrogens are on opposite sides of the double bond. Both isomers are slightly different in their physical and chemical properties, and have very different physiological properties.

Cis and trans isomers' physical chemistry indicates that they can be measured by several methods. Methods include infrared absorption spectroscopy and standard gasliquid chromatography. Infrared absorption spectroscopy can only be used with large biological samples and cannot distinguish between different trans isomers. Gas-liquid chromatography (GLC) with a packed column can be used but is not ideal because it can only distinguish some trans isomers. Many of the trans isomers of oleic (C18:1) and linoleic acid (C18:2) can, however, be resolved by high-resolution glass capillary gas liquid chromatography (GLC) (Ulberth \& Henninger, 1994). With this tool, it is now possible to obtain more information on the fatty acid composition of foods that contain trans fatty acids.

Although geographically Mexico is indeed in the West, its food has been influenced by Eastern concepts and has developed for at least six thousand years (Condon \& Condon, 1988). From the pre-Hispanic cultures of the Olmec, Maya, and Aztec, food had always played an important role in ceremonial and ritual life of Mexico. However, upon the invasion of the Spanish into Mexico, these "great traditions" were either merged among themselves, lost, or took on new combined forms with the new Spanish influence.

Mexico is a great country. It has an interesting history of many magnificent ancient cultures, a rugged topography, and a vastly diverse plant and animal life. These cultural and geographic factors are largely responsible for the wide variations in cooking methods and ingredients used in Mexican foods (Kennedy, 1978). 
Mexican ingredients are, in most cases, simple and natural. Herbs and condiments are used to give Mexican food its unique flavor and scent. Mexican food is exquisite because it is lighter and more natural (Condon \& Condon, 1988).

One of the main ingredients of traditional Mexican foods is lard. From the 129 Mexican recipes Condon and Condon (1988) list in their book, !Ole Mole!, 38 use lard as their fat source. However, in the transition between the Mexican food eaten in Mexico and the Mexican food eaten in the United States, some of the ingredients have been replaced. In Mexico, as mentioned above, ingredients are mostly natural and have very little processing. Lard used in Mexico is simply obtained by rendering pork fat and has no further processing. In contrast, the lard used in the U. S is hydrogenated and deodorized after obtained, with the purpose of extending its shelf life and making it look more appealing. However, these hydrogenation and deodorization processes produce chemical changes in this fat. As a result, Mexican foods consumed in Mexico and Mexican foods consumed in the U.S. differ in their nutritional quality. This nutritional quality has not been evaluated in the Mexican food consumed in the U.S.

Fatty acid content of non-hydrogenated lard has been analyzed extensively. Most, if not all, cis fatty acids have been found and measured in this non hydrogenated lard. Several studies report a high oleic acid content for non hydrogenated lard; content that ranges between 35 and $62 \%$ of total fatty acids (Gunstone, Harwood \& Padley, 1986). Despite this information on fatty acids, trans fatty acid content has not been reported in this non hydrogenated lard. Since non hydrogenated lard has a high content of oleic acid, it is expected that if this fat undergoes industrial processing or heating some of that oleic acid content will transform into oleic acid isomers, the most prominent being the trans-9octadecenoic (elaidic acid). 
In response to the growing health and dietary concerns of the American public, a vast variety of foods and fat sources sold on the American market have been analyzed for their content of trans unsaturated fatty acids (Enig, Pallansch, Sapugna \& Keeney, 1983). However, Mexican foods and non hydrogenated lard have largely been ignored. The lack of research on these foods is surprising given that Mexican dishes are consumed by the increasing Mexican-American population of the United States and are becoming more popular with non-Hispanic groups. Due to the possible adverse effect of trans fatty acids to the human body, an evaluation of the content of trans fatty acids in the non hydrogenated lard, as well as in the Mexican foods that are sold in the US is needed.

\section{Objectives}

The objective of this study was to determine the trans-9-octadecenoic acid (elaidic acid) concentrations in a non hydrogenated lard sample and in traditional Mexican dishes sold in the US market, prepared using lard as a source of fat, by using high performance gas liquid capillary chromatography techniques.

\section{Significance of the Study}

Mexican-American populations in the USA have increased and continue to grow rapidly. The varieties of Mexican foods sold in the grocery stores in the USA have also increased. Mexican foods are not only consumed by Mexican-Americans, but also by the general population living in the USA.

Traditional Mexican foods are prepared using specific ingredients. One of them is lard as a source of fat. In Mexico people obtain this source of fat from local meat markets. This lard is obtained only by rendering pork fat tissues and has no further processing. In the USA, rendered pork fat tissues are hydrogenated and deodorized after rendering. Hydrogenation produces certain chemical changes in the fat as well as changing its physical properties. These changes include changes on the structure of the 
fatty acids composing the triglycerides molecules off the fat. Trans fatty acids are formed in this process. Trans fatty acids have been proven to increase the risk of cardiovascular disease. They affect specific metabolic pathways in the human organism.

Many kinds of foods have been analyzed for trans fatty acids content. However, Mexican foods sold in the USA have not been studied. In order to assess the risk of cardiovascular disease, not only among the Mexican-American population, but also in the non-Hispanic population in the USA, measurement of the amounts of these geometrical isomers for these kinds of food products is needed.

\section{Review of Literature}

\section{Fats and Oils}

Over the past 67 years, an increase of $27 \%$ in the total dietary fat intake has been observed; this increase mostly due to vegetable fats. People have been encouraged to consume more vegetable fats than animal fats, with the purpose of increasing the dietary polyunsaturated fatty acids' levels at the expense of saturated fatty acids. However, the shift from animal fats to vegetable fats is more complex than might be thought, as most of the vegetable fats ingested by Americans are chemically processed. Vegetable fats are transformed by partial hydrogenation procedures to products with more profitable physical properties (Enig, Pallansch, Sampugna \& Keeney, 1983). The result of these changes in the eating habits of Americans, along with variations in the economics of the U.S. food supply, has been an increased use of processed vegetable fats and oils, relative to animal fat intake. The result has been an increased consumption of chemically altered fatty acids (FAs), known as trans FAs. Based on published fats and oils data and actual fat intake data, dietary trans fatty acids intake for the U.S. adult following a typical U.S. diet has been predicted to be between 11.1 to $27.6 \mathrm{~g} /$ person/day (Enig, Atal, Keeney \& Sapugna, 1990). However, at the present time this consumption of trans fatty acids could be higher 
considering that hydrogenated vegetable oils' consumption has increased over the past five years.

Physical, chemical, and physiological properties of fats make them very important in human nutrition and in food technology (Brisson, 1981, p. 1). Lipids, or fats, have been described as a wide variety of natural products including fatty acids and their derivatives, steroids terpenes, carotenoids and bile acids, commonly soluble in organic solvents such as diethyl ether, hexane, benzene, chloroform or methanol (Christie, 1982, p. 1)

Lipids are essential components in the human diet. They function as important energy sources since they can be stored and used when there is a need for energy; a gram of fat contains $37 \mathrm{~kJ}$ of energy compared with $16 \mathrm{~kJ}$ for a gram of carbohydrate. They are also necessary components of each living cell since they have specific metabolic or physiological functions in the human body. In addition, lipids are of vital importance in cell membrane structure.

Fats and oils are composed of one or more triglycerides. A triglyceride is an ester of glycerol with a fatty acid (Holley \& Phillips, 1995). The basic structure of lipids are fatty acids. These compounds are made up of carbon, hydrogen and oxygen. Molecules of fatty acids consist of 4 to 26 carbon atoms linked to one another to form a chain varying in length (Brisson, 1981, p. 1).

Properties and behavior of fats are dependent on the structure and configuration of the fatty acids, specifically in the length of the C-C chain; the shorter the fatty acid chain, the lower the melting point of the fat. Along with the length of the fatty acid chain, the nature of the bonds between carbon atoms in the chain also plays a role in the properties and melting point of the fat. The carbon atom is able to form either single, double, or triple bonds. Triglycerides from fats and oils may be made up from fatty acids containing triple, double, and single carbon bonds in their carbon chain. 
Double bonds are constituted of a single bond, known as a sigma bond, and a second, weaker bond, the $\pi$ hi bond. Double bonds are weaker than two single bonds. Single covalent bonds link the carbon chain in saturated fatty acid and the remaining bonds are taken up by hydrogen atoms.

Carbons in unsaturated fatty acid chains have at least one double bond. Double bonds are highly reactive. The point in the chain where the double bond is located is vulnerable to the attack by chemicals, and can also be transformed by heat. Double bonds make unsaturated lipids much more susceptible to spoilage.

Saturated fatty acids' chains joined by single bonds allow the carbon chain to rotate freely, something that does not occur in unsaturated fatty acids containing one or more double bonds joining the carbon-carbon chain. The double bond in unsaturated fatty acids stops the carbon chain from rotating freely. As a result two possible structures with identical chemical composition may occur. These two structures are recognized as cisand trans- isomers (See figure 1).

Figure 1. Cis- and Trans-isomers of octadecenoic acid

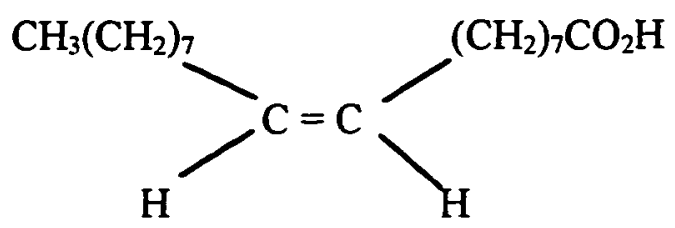

Cis-9-Octadecenoic acid<smiles>C=C(CCCCCCC)CCC(=O)O</smiles>

Trans-9-Octadecenoic acid

Trans fatty acids (TFAs) are unsaturated fatty acids containing one or more double bonds. Naturally occurring unsaturated fatty acids are in the cis configuration, meaning the hydrogen atoms are located on the same side of the double bond (Giese, J., 1996). The presence of TFAs in fat-based products, such as margarine and lard, is partly a result of industrial processes to transform liquid vegetable oils to solid or semi-solid fats. This 
process is known as hydrogenation, since hydrogen atoms are added to the $\mathrm{C}=\mathrm{C}$ double bond. Oils and semi-solid fats are heated and mixed with finely divided nickel. The hydrogen is added under pressure to produce a close contact with the oil, increasing the reaction speed. Some of the unsaturated fatty acids will be converted to saturated fatty acids. Hydrogenation can be controlled to produce a fat of any hardness. During hydrogenation, some rearrangement of the fatty acid structures also occurs.

Fatty acids containing one or more double bonds may undergo rearrangements such as the repositioning of the double bonds in fatty acids and rotation of the carbon chain containing double bonds. The repositioning of the double bonds in fatty acids is known as positional isomerism and the rotation of the carbon chains containing one or more double bonds joining the carbon-carbon chain is known as geometrical isomerism. Trans fatty acids are formed as a result of geometrical isomerization of cis fatty acids containing one or more double bonds.

Although hydrogenation processes do not change the chemical composition of the fat, they transform its fatty acids' structures from cis to trans fatty acids' structures. This transformation in turn changes the physico-chemical (see Table 1) and biological properties of fatty acids. 
Table 1. Physicochemical Properties of 9-Cis- and 9-Transoctadecenoic Fatty Acid Isomers

\begin{tabular}{|c|c|c|}
\hline & 9-Cis-octadecenoic fatty acid & 9-Trans-octadecenoic fatty acid. \\
\hline Name & Oleic Acid & Elaidic Acid \\
\hline $\begin{array}{l}\text { Molecular } \\
\text { Formula }\end{array}$ & $\overline{\mathrm{C}_{18} \mathrm{H}_{34} \mathrm{O}_{2}}$ & $\mathrm{C}_{18} \mathrm{H}_{34} \mathrm{O}_{2}$ \\
\hline $\begin{array}{l}\text { Molecular } \\
\text { Weight }\end{array}$ & 282.45 & 282.45 \\
\hline $\begin{array}{l}\text { Melting } \\
\text { point }\left({ }^{\circ} \mathrm{C}\right)\end{array}$ & 13.4 & 45 \\
\hline $\begin{array}{l}\text { Boiling } \\
\text { point }\left({ }^{\circ} \mathrm{C}\right)\end{array}$ & $286^{100}$ & $288^{100}$ \\
\hline $\begin{array}{l}\text { Density } \\
\left(\mathrm{g} / \mathrm{cm}^{3}\right)\end{array}$ & $0.8935^{20}$ & $0.8734+5$ \\
\hline $\begin{array}{l}\text { Refractive } \\
\text { Index: }\end{array}$ & $1.4582^{20}$ & $1.4499+5$ \\
\hline Solubility & $\begin{array}{l}\mathrm{H}_{2} \mathrm{O} 1 ; \\
\text { Al 5; } \\
\text { Eth 5; } \\
\text { Ace 5; } \\
\mathrm{Bz} \mathrm{5;} \\
\text { Ctc 5; } \\
\text { Chl 5; MeOH } 5 \text {. }\end{array}$ & $\begin{array}{l}\mathrm{H}_{2} \mathrm{O} 1 \\
\mathrm{Al} 3\end{array}$ \\
\hline
\end{tabular}

Some cis-fatty acids are recognized as essential fatty acids, as they play a key role for a variety of metabolic functions. Essential fatty acids are linoleic acid, linolenic acid, and arachidonic acid. The position of the double bonds plays a key role. Essential fatty acids have a double bond between nine and ten in the chain (Holley \& Phillips, 1995).

From the nutritional standpoint, it is hypothesized that the presence of trans fatty acids in fats and foods may induce modifications of biochemical processes (Desmedt, Culot, Deroanne, Durant \& Gibon, 1990). In vitro and in vivo studies have demonstrated that each trans fatty acid isomer is biochemically different. They have also demonstrated that the double bond position can be biochemically as important as the double bond 
configuration in an unsaturated fatty acid isomer. These observations go along with the differences in the physical properties of individual fatty acid isomers and differences in the conformation of the fatty acid chain due to the double bond configuration and positions. Figure 2 shows the possible conformations of cis and trans octadecenoic acid isomers. Although the present state of knowledge about trans fatty acid biochemical properties is better than 10 years ago, there is still much to be discovered (Emken, 1983).

Figure 2. Possible conformations of octadecadienoic acid isomers.

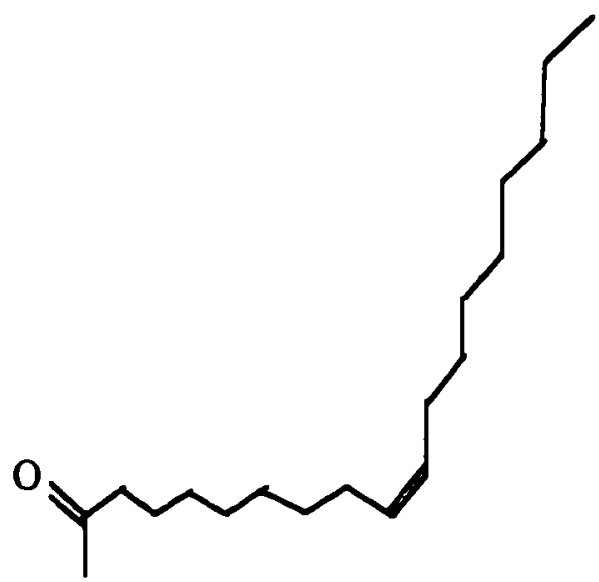

$\mathrm{OH}$

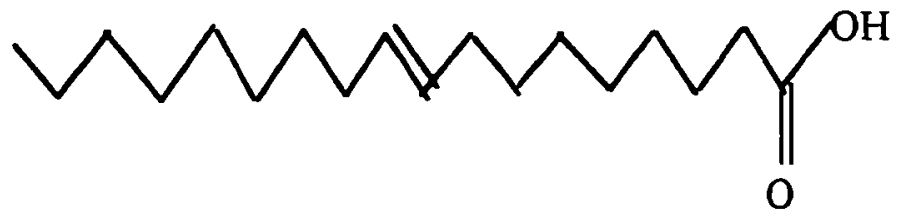

Trans-9-Octadecenoic acid

Unprocessed fats from plant sources carry only cis-isomers, while animal fats are mostly made up of cis-isomers, but may contain a small proportion of trans-isomers (Holley \& Phillips, 1995). However, these plant and animal fats are not consumed in their natural forms by the American population. Rather, these fats undergo heavy industrial processing such as hydrogenation or heating which changes the structure of its fatty acids. Due to this processing, many of the foods consumed in the U.S. have been proven to contain considerable amounts of trans fatty acids (see Table 2). 
Table 2. Trans Fatty Acid Content of Selected Food Items

\begin{tabular}{|c|c|c|c|}
\hline Food Item & \multicolumn{3}{|c|}{ trans Fatty Acid ( $\%$ of total Fatty acids) } \\
\hline & Minimum & Maximum & Average \\
\hline Milk fat ( $81 \%$ fat) & $1.9 \mathrm{a}$ & $8.6^{\mathrm{b}}$ & \\
\hline Butter & $4.3^{c}$ & $7.6^{d}$ & \\
\hline $\begin{array}{l}\text { Margarines } \\
\text { Hard } \\
\text { Soft } \\
\text { Diet }\end{array}$ & $\begin{array}{l}16-17 \\
10\end{array}$ & $\begin{array}{c}35-36 \\
30\end{array}$ & 15 \\
\hline Commercial frying fats $\mathrm{e}$ & 40.4 & 42.4 & 41.5 \\
\hline $\begin{array}{l}\text { Household vegetable } \\
\text { shortenings }{ }^{e}\end{array}$ & 13.0 & 37.3 & 25.3 \\
\hline $\begin{array}{l}\text { Snack Items } \\
\text { Com Snackse } \\
\text { Cheese Snacks } \\
\text { Donutsg } \\
\end{array}$ & $\begin{array}{l}0.8 \\
23.5 \\
32.5\end{array}$ & $\begin{array}{l}22.0 \\
53.9 \\
36.7\end{array}$ & \\
\hline $\begin{array}{l}\text { Processed Foods } \\
\text { Bread and rolls } \\
\text { Bread mixes and fried } \\
\text { crusts } \\
\text { Candy and frostings } \\
\text { Cream Substitutes, } \\
\text { cereals, puddings } \\
\text { Cookies } \\
\text { Crackers } \\
\text { Snack Chips } \\
\text { Pastries and pastry crusts } \\
\text { Pizza crusts and pretzels } \\
\text { Fried potatoes }\end{array}$ & $\begin{array}{l}0 \\
0 \\
0 \\
0 \\
0 \\
0 \\
0\end{array}$ & $\begin{array}{l}27.9 \\
33.5 \\
38.6 \\
36.1 \\
37.4 \\
31.6 \\
33.4 \\
34.6 \\
31.4 \\
36.2\end{array}$ & $\begin{array}{l}10.1 \\
12.9 \\
15.8 \\
10.7 \\
18.7 \\
12.2 \\
11.9 \\
10.3 \\
10.1 \\
13.9\end{array}$ \\
\hline
\end{tabular}

a Smith et al., 1978

b Woodrow and deMan, 1968

c Parodi and Dunstan, 1971

d deMan and deMan, 1983

e Enig, et al., 1983 data expressed as percent methyl esters.

f Smith et al., 1986

${ }^{8}$ Enig, et al., 1990 


\section{Biological Effects of Trans-fatty Acids}

The first reported separation of cis-trans fatty acid isomers was in 1956 by James and Martin. However, it was not until the 1960's that the idea that trans fatty acids could exert adverse effects in the human body was accepted. According to several experimental and epidemiological studies, these adverse effects have been confirmed. People are now aware that they can take care of their health by watching the foods they eat, especially when these foods have a high concentration of fats. The U.S. government is working in changing food labeling laws to include in the label information on the presence and concentration of trans fatty acids in foods.

In recent years, fats and oils have become the subject of contradictory research, with much debate focused on the role trans-fatty acids play in coronary heart disease, arteriosclerosis development and unfavorable lipoprotein profiles (Holley, K. M. \& Phillips, P. S., 1995). In addition, to prove the effects of industrial chemical processing of fats, analyses of human tissue have shown that the major source of trans fatty acids to the U.S. diet are hydrogenated fats and oils (Emken, 1983). Trans-fatty acids may be harmful and cannot be used as essential fatty acids by the body since enzymes do not recognize their forms. Evidence from experimental studies has shown that dietary 18-carbon fatty acids with a single trans double bond increase the concentration of low density lipoprotein (LDL) cholesterol in the blood when compared with a similar amount of dietary 18-carbon cis-monosaturated fatty acids (with oleic acid being the most abundant 18-carbon cis monosaturated fatty acids). Judging by the effect of trans fatty acids on plasma lipoprotein concentrations, the current view is that consumption of high levels of trans fatty acids should increase cardiovascular disease (CVD) (Holley, K. M. \& Phillips, P. S., 1995). 
Some epidemiological and clinical evidence have also suggested that trans fatty acids may be associated with higher total blood cholesterol and LDL cholesterol concentrations and increased incidence of coronary hearth disease. However, according to many reviews, the reported data is inconsistent. What remains to be establish is the independent and the relative cholesterolemic effects of trans fatty acids. In any case, any potential cholesterol-raising effect of trans fatty acids is less than that of cholesterolraising saturated fatty acids (Giese, J., 1996).

In addition, epidemiological data have suggested that trans fatty acids may have an adverse effect on the metabolism of essential fatty acids (EFA). They can either inhibit the 6-desaturase, or compete for enzymes in the alternate desaturation and elongation of linoleic and alpha-linoleic acids to their long chain polyunsaturated products (Holley, $\mathrm{K}$. M. \& Phillips, P. S., 1995).

Koletsko (1992) found that maternal intake of trans fatty acids affected the birthweight of premature infants as a result of interference with EFA metabolism. Decsi and Koletzco (1995) assessed whether trans fatty acids impaired EFA metabolism in healthy children. Their findings showed that trans fatty acids inhibit the biosynthesis of arachidonic acid. Long chain polyunsaturated fatty acids, like arachidonic acid, are of key importance for tissue growth and development. Decsi and Koletzco (1995) questioned the safety of dietary trans fatty acids' intakes in childhood.

In their paper, Katan, Zock and Mensink (1994) discussed some of the effects of the different fatty acids on LDL cholesterol, high density lipoprotein (HDL) cholesterol, and lipoprotein (a) (Lpa). They stated that trans fatty acids raise LDL cholesterol concentrations, decrease plasma HDL cholesterol concentrations, and in some cases raise the plasma concentrations of $\mathrm{Lpa}$, an atherogenic lipoprotein. They also mentioned that these raises on LDL cholesterol were lower than those caused by saturated fatty acids. 
Aro, Kardinaal, Salminen, Kark, Riemersma, Delgado-Rodriguez, GomezAracena, Huttunen, Kohlmeier, Martin, Martin-Moreno, Mazaev, Ringstad, Van't-Veer and Kok (1995) conducted an EURAMIC study investigating the relationship between adipose tissue isomeric trans fatty acids and the risk of myocardial infarction (AMI) in nine countries. They found considerable differences between countries in dietary intake of trans fatty acids, but did not suggest a major overall effect of C18:1 trans fatty acids on risk of AMI. However, they said that the possibility that trans fatty acids have a significant impact on risk of AMI in populations with high intake can occur can not be excluded. In addition, strong limitations were found in this study.

Roberts, Wood, Riemersma, Gallagher and Lampe (1995) studied the association between trans isomers of oleic and linoleic acid in adipose tissue and sudden cardiac death and found a negative association between trans oleic acid and risk of sudden cardiac death. However, they did not find any association with trans forms of linoleic acid. The effect of dietary trans fatty acids on blood pressure was also studied and the researchers did not find any correlation between blood pressure and intake of trans fatty acids (Mensink, De Louw \& Katan, 1991).

Results from a survey research study performed by Willet, Stampfer, Manson, Colditz, Speizer, Rosner, Sammpson and Hennekens (1993) indicated that women consuming on average $5.7 \mathrm{~g} /$ day of trans fatty acids were $50 \%$ more likely to develop cardiovascular disease.

\section{Mexican Food}

Mexican food has been regarded by many experts as being one of the major ancient cuisines of the world. Drawing from a rich cultural history, Mexican cooking is as diverse as its people and geography (Piotrowski, 1995, p. 5). Ancient Mexican Indian traditions, as well as those traditions introduced by the Spanish, have helped shape the diversity 
found in Mexican food today. The geography has also played an important role in the incredible variety of foods Mexico offers. With the Pacific Ocean to the west and the Gulf of Mexico to the east, and to its northern and southern boundaries of North America and Central America, Mexico's landscape is a scene of ever-changing terrain and climates. In Mexico can be found deserts to the north, jungles and rainforests to the south, and coastal areas, mountains, and high plains to the east and west. This diverse land results in extremely localized agricultural practices. Consequently, much of Mexican cuisine is regional (Peyton, J. W., 1995, p.4).

Mexican cooking is largely founded in the traditions of the ancient Indian civilizations which once ruled. Unlike its American neighbor to the north, Mexican cooking has been, and still is, about the symbiotic relationship between man and nature. Mexican food has a richness of health. Nutritional studies of the diets of the Otomi Indians in the Mezquital valley of Central Mexico have provided evidence of the healthfulness of traditional Mexican foods. Unaware of the strict Western dietary requirements for good health, the Otomis have lived on tortillas and local plants, a traditional Indian diet, demonstrating the nutritional completeness of the Mexican diet. The same nutritionally balanced diet can be found in the tortilla, corn, and bean diets of rural Mexico. Perhaps the factor most responsible for the nutritional balance of the Mexican diet is the variety of fruits, vegetables, and other ingredients used in Mexican cuisine. According to Condon and Condon (1988), Mexican people believe that eating better food equates to a better and longer life. Indeed, they have found that Mexican people living in Mexico do live longer than Mexicans or Americans living in the United States. The rawness and simplicity of Mexican ingredients may account for this finding (Condon, R., \& Condon, W., 1988. p. 3-25). 
The preparation of Mexican food in Mexico is greatly different from the preparation of Mexican food in any other country in the world. It differs not only in presentation and flavor, but also in nutritional value. These differences can be attributed to the variations in ingredients used. Much to the chagrin of the health-conscious American, many Mexican dishes are prepared with lard as a source of fat. These include many traditional Mexican dishes such as tamales, chiles rellenos, refried beans, gorditas, flour tortillas, frijoles rancheros, and many others. Unlike commercial lards found in the United States which are industrially processed after rendering, Mexican lard is naturally obtained by rendering pork fat and has no further processing. This difference may account for the different chemical composition of the fat. Consequently, this may be the reason why the nutritional quality of Mexican food in the United States is lower than the Mexican food found in Mexico.

Lard

Animal fat is characterized by its low level of unsaturation and by the presence of small amounts of trans fatty acids resulting from rumen biohydrogenation. Rumiant depot is obtained commercially from animal tissues by rendering. The process of the manufacture of lard includes the heating of the tissues by steam in the absence of water or added water. Liquid fat and protein solids are removed after cooling and separated by centrifugation or pressing (Gunstone, F. D., Harwook, J. L., \& Padley, F. B., 1986). The rendered lard is a semi-solid liquid at room temperature. It is not completely solid because of its high content of unsaturated fatty acids (particularly oleic acid). This lard is commonly used in Mexico to prepare its traditional dishes.

Commercially, highly unsaturated fats or oils are not suitable for many food fats because they have very low melting points and are more susceptible to oxidative deterioration. To overcome these problems, the degree of unsaturation is reduced by 
hydrogenating the fat or oil. Hydrogenation of fats is a chemical reaction consisting of the addition of hydrogen at double bonds of unsaturated acyl groups. Commercially sold lard is hydrogenated to extend its shelf life and increase its melting point so that it can be easily manipulated by food manufacturers. Most lard sold in the U.S. has undergone hydrogenation processes to decrease deterioration of the fat.

Most hydrogenation of fats and oils is not carried out to the complete saturation of the fats' unsaturated fatty acids. With a careful choice of catalyst and temperature, the oil or fat can be selectively hydrogenated to achieve a product with precisely the desired characteristics (Gurr, 1992, p. 45). In the hydrogenation reaction, gaseous hydrogen, liquid or semi-liquid oil, and solid catalyst participate under agitation in a closed vessel. During hydrogenation, the phenomenon of isomerization occurs. A proportion of the cis double bonds in natural oils are isomerized to trans double bonds. In addition there is also a migration of double bonds along the chain. So if the natural fat contained a high proportion of double bonds between the 9th and 10th carbon atoms along the chain, then partial hydrogenation products would contain double bonds that are more widely distributed (Gurr, 1992, p. 45).

Despite the compositional changes in fatty acids caused by hydrogenating lard, its composition also varies widely and depends on feed and origin, including animal type and location of fat on the animal. Table 3 lists the major fatty acids of partially hydrogenated lard, but many more have been identified (Enig, Pallansch, Sammpugna \& Keeney, 1983). Animal fats are noted for the presence of odd-numbered, branched-chain and trans fatty acids (Gunstone, F. D., Harwook, J .L., \& Padley, F. B., 1986). 
Table 3. Fatty acids' composition of partially hydrogenated lard, (as weight percentage of methyl esters)

\begin{tabular}{|c|c|}
\hline Fatty acid & Partially hydrogenated lard \\
\hline $14: 0$ & 1.4 \\
\hline $16: 0$ & 24.8 \\
\hline $16: 1$ & 3.2 \\
\hline $18: 0$ & 14.2 \\
\hline $18: 1 \mathrm{t}$ & 0.3 \\
\hline $18: 1 \mathrm{c}$ & 42.4 \\
\hline $18: 2 \mathrm{c}$ & 12 \\
\hline others & 1.6 \\
\hline
\end{tabular}

Adapted from Enig, Pallansch, Sammpugna \& Keeney, 1983.

Trans fatty acid content in partially hydrogenated lard has been determined to be $0.3 \%$ of total fatty acids (Craig-Schmidt, M. C. 1992). This trans fatty acid normally would be lower for the non hydronated lard used in Mexican foods preparation in Mexico.

\section{Chromatography}

With the increasing public awareness of health issues relating to saturated fats and trans fatty acids in the diet, manufacturers are looking for a simple method to determine these fatty acid isomers; a method that could be used by a trained technician to plough through hundreds of samples a day (Ratnayake, W. M. N., \& Beare-Rogers, J. L., 1990). Still, up to the present day, there is no method to determine trans fatty acids that can simply be given to a trained technician. Determination of trans fatty acids requires a skilled analyst with interpretative ability. The use of gas chromatography techniques to determine the percentage of saturated fatty acids and trans fatty acids in margarine, oils, spread, and foods are currently the method of choice because of its accuracy and reliability. However, since small changes in chromatographic conditions can affect the results of the analysis, this technique is still geared toward the skilled analyst, not the novice (Christie, 1995). 
Chromatography had revolutionized the world since its invention in the 1930's. It has become a standard item in most laboratories involved in health and food testing. It is of key importance in health checks for toxins, quality control, developing synthetic flavors and aromas, checks for drugs, and perhaps one its most useful applications is in the analysis of lipids, in the determination of the fatty acid compositions of lipids. Today, food manufacturers are using chromatographic techniques to determine the percentage of saturated fatty acids and trans fatty acids in margarines, oils and spreads as well as determining the percentages of essential fatty acids in triglycerides consumed by the population (Holley, Pennington \& Phillips, 1995).

For the separation and/or determination of cis and trans isomers of unsaturated fatty acids, several chromatographic methods have been devised. Variations of the chromatographic procedure conditions and column types used have been tested. However, findings have not been satisfactory (Christie, W. W., \& Breckenridge, G. H. McG., 1989).

Glass Capillary chromatography with highly polar stationary phases and long column lengths have been tested, giving acceptable but not ideal results (Christie, W. W., \& Breckenridge, G. H. McG., 1989). The analysis is still time consuming, confusing and the quantitative analysis of food lipids still relies heavily on the accurate setting up and calibration of instrumentation (Hammong, E. W., 1981).

Despite the extensive research done with the purpose of finding a single and simple chromatographic method to determine trans unsaturation of fats and oils, there has been no success. For this determination, the best results have been obtained by a combination of gas liquid chromatography using glass capillary columns with silver ion chromatography. However, up to the present time, this method involves too many steps that can confuse the analyst, and can be very time consuming (Sampugna, J., Pallansch, L. A., Enig, M. G., \& Keeney, M., 1982). 


\section{Columns}

Columns are made up of a steel or glass tube packed with an inert packing material. However, glass columns have been recognized for a long time to have superior performance characteristics over steel columns. The glass columns' surface is less likely to react with substances being analyzed chromatographically, and the column defects' are more apparent and can be diagnosed (Jennings, 1978, pp. 19,20). In gas-liquid chromatography (GLC), these columns' packing materials are coated with an involatile liquid, so that the surface area of the liquid in contact with the gas is large (Holley, K., Pennington, M., \& Phillips, P., 1995).

In gas chromatography there are two types of columns: the packed column and the capillary column. Capillary columns have been shown to be superior to packed columns because they have better resolution (efficiency in separating components) and lower adsorption effects (Mukherjee \& Weber, 1993, p. 139).

The mixture of compounds is injected into the carrier gas steam. Then the molecules of each compound present in the mixture will distribute between the gas and the liquid, as it is carried through the column (Holley, K., Pennington, M., \& Phillips, P., 1995). Each molecule of the sample compounds will constantly move between the gas and the liquid in a dynamic equilibrium. When molecules are in the gas phase they will pass along the column, when they stay dissolved in the liquid they will be stationary.

The lifetime of the columns depends on the durability of the tubing and the stationary phase and it is influenced by several factors, such as oxygen and water contents of the carrier gas, operating temperature, type of solvents used, reagents and nonvolatile constituents of the sample (Mukherjee \& Weber, 1993, pp. 140, 141, 376). 


\section{Stationary Phase}

Gas liquid chromatography (GLC) separation occurs as a result of selective interactions between the solute and the stationary liquid phase. As mentioned above, all solutes spend the same length of time in the gas phase. The principal intermolecular interactions that occur between a solute and a solvent are dispersion, induction, and orientation and donor-acceptor interactions, including hydrogen bonding (Poole, C.F., \& Shuette, A. S. 1984).

The polarity of the stationary phase absorbed in the column packing material plays a key role in the distribution of sample compounds among it. Polarity indicates how sample compounds interact with the stationary phase. Separation between substances in a sample is based on their boiling points when the column stationary liquid phase is a non polar component. Therefore, the more volatile a substance, the greater proportion of time its molecules will be carried by the mobile phase, and the sooner it will emerge from the column. In this process, each substance from the sample will become separated with the column and emerge separated by time at end. (Holley, K., Pennington, M., \& Phillips, P. 1995). On the other hand, when the column is coated with a polar stationary phase, this phase retards compounds based on both boiling point and induced dipole interaction or hydrogen bonding. Polar and strongly polar phases retain polar compounds longer than non polar compounds due to the dipole-dipole interactions between the functional groups of the sample and the stationary phase (Poole \& Schuette, 1984, chapter 2).

It is preferred for the liquid phase (stationary phase) to have a wide temperature operating range, have a low vapor pressure, and be chemically stable. The most important group of liquid phases are the polysiloxanes. Their high thermal stability, wide liquid range, and availability in different polarities, contribute to their notoriety. The basic siloxane backbone can be represented by structure (I), in which $R$ can be either methyl, 
vinyl, phenyl, 3,3,3-trifluoropropyl, cyanoethyl, or cyanopropyl groups. Many polymers contain mixtures of the above functional groups.

For GLC of triacylglycerols, two kinds of stationary phases are used in capillary columns: (1) apolar silicones, examples are methylsilicones, partly with $5 \%$ phenyl content and; (2) intermediate polar silicones, i.e., phenylmethylsilicones with 50 to $65 \%$ phenyl content.

For gas chromatography of fatty acid methyl esters in capillary columns two kinds of stationary phases are used: (1) polyethylene glycols and (2) methyl silicones with different cyanopropyl content and those with some phenyl content. For GLC of trans fatty acid methyl esters highly polar cyanosilicone stationary phases are commonly used (Mukherjee \& Weber, 1993, p. 140, 141, 376). Commonly cyanopropylsilaxone stationary phases have been used in the determination of trans fatty acids. The polar stationary phase SP-2340 is even listed in the official method of analysis by the AOAC. Despite this, several studies have shown that this polar phase does not give satisfactory separations, and overlaps occur between the different double bond systems. Because of these overlaps, fatty acid isomers can not be determined by GLC alone on the SP-2340 liquid phase or any other cyanosilicone phase. Advances in science have developed non polar stationary phases that can be used for the detection of trans fatty acids. However, these phases have not been extensively tested.

Detector

Two types of detectors are commonly used: Thermal conductivity and flame ionization. However, for our purposes we will only cover the flame ionization detector (FID). 
Since in food analysis many of the compounds under investigation are organic, and the FID is approximately a thousand times more sensitive than the thermal conductivity detector for organic compounds, it is more frequently found in food applications.

In this kind of detector the gas emerging from the column is burned with a hydrogen and air mixture. The burning of the sample molecules forms ions, which conduct an electric current that can be amplified and recorded on a chart recorder. Although the number of ions formed in this way is small, perhaps only 0.0001 per cent of the total carbon atoms present in the sample, the proportion produced is always constant, meaning that the total signal recorded on the chart recorder is proportional to the amount of the chemical substance present (Holley, K., Pennington, M., \& Phillips, P. 1995).

Chromatographic Applications in Food Analysis

Since 1958, gas liquid chromatography (GLC) has established itself as an essential instrument for fats and oils' research (Litchfield, Reiser \& Isbell, 1963). GLC analysis of fats and oils is not only used to the characterization of fatty acid mixtures, but it is also capable of separating cis and trans isomers of individual fatty acids (Musgrove, 1988). Lipids analyzed by GLC need to be extracted from the food sample and prepared, before the chromatographic analysis. In many cases direct injection is not possible because it would cause non-volatile solids to be deposited on the column, and would contaminate and destroy an expensive column very quickly. The use of gas chromatography in the determination of the fatty acid content of triglycerides (fats and oils) is very important. However, fatty acids are not volatile enough to pass through the gas chromatography column. They must first be transformed to a more volatile form that still keeps the original fatty acid (Holley, Pennington \& Phillips, 1995). 
Extraction and Transformation of the Fat Sample for Chromatographic Analysis

\section{Extraction}

Food substances are commonly analyzed by GLC. However, some of them need some kind of extraction from the food sample before analysis. Direct injection would contaminate the column by depositing non-volatile solids on it. Extraction is one of the most critical steps in the analysis of foods for total fat, fatty acid composition, and neutral and polar lipids (Sahasrabudhe \& Smallbone, 1983).

Extraction using liquids to solubilize all or a part of the sample matrix is widely used. Solvent extraction techniques can be applied to vapors, liquids, and solids and have the following advantages: A large selection of pure solvents providing a wide range of solubility and selectivity is available, equipment requirements are simple, and solution phase samples are convenient and compatible with the sampling requirements of chromatographic instruments.

Samples having many different substances to analyze require a mixture of solvents to extract all of the different substances desired. A single solvent in most cases is not able to extract all components, causing discrimination and a biased analysis. In certain cases, discrimination may be useful if the solvent discriminates against the extraction of solutes that are of no interest in the analysis.

The extracting solvent efficiency is dependent primarily on the affinity of the solute for the extracting solvent $\left(K_{D}\right)$, the phase ratio $(V)$, and the number of extractions $(n)$. For simple extraction $\mathrm{K}_{\mathrm{D}}$ should be large, as there is a practical limit to the phase volume of the extracting solvent and the number of extractions that can be performed before the method becomes tedious and results in a very dilute sample extract. 
The selection of the extraction process plays a key role in the extraction of the components to be analyzed. It can be both a strength and a weakness when applied as a sampling technique.

Liquid extraction uses large solvent volumes compared to the sample volumes that can be analyzed chromatographically. This dilution of the sample is often too great for direct determination without a concentration step. Large sample volumes may be evaporated using a rotary evaporator under reduced pressure to avoid the loss of the most volatile compounds. Rotary evaporators provide a convenient means of solvent evaporation under reduced pressure.

In general, the actual method of extraction and evaporation of the sample depends on the nature of the sample and the type of extract desired. Only a few lipids can be extracted by a single solvent, and it is usual to employ a mixture of solvents. (Christie, 1982. p.18)

There are several mixtures of solvents used to extract lipids from food and biological materials. Several studies have used the Folch, Lees and Sloane-Stanley method (1957) of extraction because it has been the most effective and satisfactory method of extraction for subsequent determination of total fat, fatty acids and various food products. However, this method employs a chloroform-methanol $(2: 1 \mathrm{v} / \mathrm{v})$ solvent mixture, and it is well known that chloroform may have adverse effects on the health of humans (Chen, Shen \& Sheppard, 1981). Another solvent mixture that has been used to extract lipids from food samples giving good extraction results is the mixture of hexaneethyl ether, where at one phase hexane-ethyl ether rapidly extracts lipids from dried tissues. The mixture of sample and solvents is then filtrated to eliminate the non fatty solids. After the solvent is evaporated, only the extracted triglyceride is left. This mixture 
of solvents has the advantage extracting the lipid portion of the sample and does not have the potential health hazard of the Folch, Lees and Sloane-Stanley (1957) solvent mixture.

\section{Transformation}

The determination of fatty acid content of triglycerides is an important use for GLC. However, triglycerides are not volatile enough to pass through the GLC column. Lipids must be transformed into a more volatile derivative that still retains the identity of the original fatty acid before GLC analysis.

The first step in achieving this transformation is to split the triglyceride molecule, creating free fatty acids and glycerol (Holley, K., Pennington, M., \& Phillips, P. 1995). Ester or lipid hydrolysis (saponification) is effected in the laboratory by refluxing with aqueous ethanolic alkali. Acidification of the hydrolysate liberates fatty acids that can be extracted with hexane or other organic solvents. Non-acidic compounds (unsaponifiables) such as hydrocarbons, long chain alcohol's, sterols and glycerol will also be present in the organic extract, but glycerol remains in the aqueous phase. Saponification is usually carried out at around $100^{\circ} \mathrm{C}$, with glycerol being recovered as a second commercial product, and free fatty acids as the first and most important product of this process. Glycerol is separated from the solution by washing the lipid extract with water several times and eliminating the water layer (Holley, K., Pennington, M., \& Phillips, P. 1995).

Fatty acids are then converted into their corresponding esters to improve volatility and to reduce peak tailing for gas chromatography (Misir, R., Laarverld, B., \& Blair, R., 1985). The major limitation when analyzing fatty acids' composition by GLC is associated with preparation of fatty acid methyl esters (FAME). Although there are many procedures to prepare FAME described in literature, the majority of them involve either many steps or variations in the method that may lead to confusion or can create difficulties in comparing data from different studies. However, these procedures are the most 
commonly used in GLC analysis of fatty acids. Methyl esters of fatty acids are the easiest derivative of fatty acids that can be prepared. Methyl esters have the lowest molecular weight. As a result, they are able to elute from GLC columns at temperatures lower than other derivatives. However, there are other alternatives to methyl esters for derivatisation, such as butyl ester and propan-2-ol esters; the choice depends on the fatty acids to be analyzed (Christie, 1995).

Fatty acids methyl esters (FAME) formation is usually accomplished in the presence of a catalyst mixed with or dissolved in methanol. Sometimes a heat treatment is necessary for the reaction to proceed; this heat treatment is dependent on how long the reaction is allowed to proceed and which catalyst is used. There are several catalysts and they are either acidic or basic. The acidic catalysts that are normally used are hydrochloric acid( $\mathrm{HCl})$, sulfuric acid $\left(\mathrm{H}_{2} \mathrm{SO}_{4}\right)$ and boron trifluoride $\left(\mathrm{BF}_{3}\right)$. The basic catalysts used include sodium methoxide $\left(\mathrm{NaOCH}_{3}\right)$, potassium hydroxide $(\mathrm{KOH})$, and sodium hydroxide $(\mathrm{NaOH})$ (Liu, K, 1994).

FAME formation actually involves converting one ester to another since lipids are a mixture of esters. This reaction is generally referred to as transesterification. When FAME are prepared by reacting a fatty acid with methanol in the present of a catalyst, the reaction is termed methylation (esterification). Transesterification involves the cleavage of an ester by an alcohol other than methanol, whereas methylation involves the cleavage of an ester by methanol. Methylation and transesterification have some similarities. Both are reversible reactions, and both can be affected by the presence of water in the system. However, transesterification can be catalyzed by either an acid or a base, whereas esterification can only be catalyzed by a base (Park, P. W., \& Goins, R. E., 1994).

In acid-catalyzed methylation (esterification), methyl esters are made from acids by reaction with a large excess of methanol containing sulfuric acid (1-2\%), hydrogen 
chloride (5\%), or boron trifluoride (12-14\%) as a catalyst, or by reaction with diazomethane. Acid-catalyzed methylation has the advantage over basic-catalyzed methylation in that it is able of not only esterify triglycerides and other complex lipids but also esterify free fatty acids. In addition, acid-catalyzed methylation requires less rigid anhydrous conditions than basic catalyzed methylation. Water does not affect the reaction system in the acid catalyzed methylation as it does in the basic catalyzed methylation reactions (Liu, K., 1994).

Methylation of fatty acids with anhydrous $\mathrm{HCl} / \mathrm{MeOH}$ is claimed to be the best general purpose esterifying agent. However, according to many studies the stability of this reagent is limited. After finding that $\mathrm{HCl} / \mathrm{MeOH}$ had limited stability, another acid catalyst was used as an alternative: Sulfuric acid in methanol. Although, the sulfuric acid in methanol reagent was officially recognized by the Association of Official Analytical Chemist in 1965 because of its easy of preparation and its similarity to the $\mathrm{HCl} / \mathrm{MeOH}$ reagent, this reagent has been cited for decomposing polyunsaturated fatty acids under certain conditions and requiring extensive work-up. Another reagent used in the preparation of FAME is boron trifluoride alcoholate. $\mathrm{BF}_{3} / \mathrm{MeOH}$ has higher esterifiying than transesterifying capabilities, and it can be combined with alkaline hydrolysis quantitative form FAME in a shorter period of time than the time needed by the still official sulfuric acid in methanol method by the AOAC. Because of this, this method rapidly gained popularity. In 1969 it was adopted by the American Oil Chemists' Society to replace the sulfuric acid/methanol procedure. This $\mathrm{BF}_{3} / \mathrm{MeOH}$ procedure is still the most used catalyst for fatty acid methyl esters preparation. However, its popularity does not mean that it is the best. $\mathrm{BF}_{3} / \mathrm{MeOH}$ is toxic, expensive, and has a limited shelf life. The objectives of these procedures are to quantitatively transfer FAME formed into an organic solvent, to purify FAME-solvent solution, and to prevent undesirable side 
reactions that may continue to occur after the main reaction. Possible errors can occur when FAME are prepared for quantitative analysis. These errors can be failure to methylate quantitatively, failure to transfer esters quantitatively into an organic layer, evaporative losses of esters during work-up group or storage, and saponification of esters after methylation. In any case, controlled conditions are required to achieve success in the preparation of FAME. Finally, the obtained methyl esters are quantitatively diluted in a solvent and then they can be injected directly into the chromatograph (Liu, K., 1994).

Several methods of direct transmethylation have been described. Methods that involved less necessary steps than the normally used transmethylation method involving drying, extracting, purification or evaporation, a base hydrolysis, methylation, and postreaction work-up procedures. Direct transmethylation would include drying, transmethylation, and post-reaction work-up transmethylation. Although, many studies have reported positive results from in situ or direct transmethylation of biological materials, there is still concern that in situ transmethylation of lipids may encounter interferences or side reactions as a result of the complex mixture of chemical substances that characterize biological materials (Liu, K., 1994; Misir, R., Laarveld, B., \& Blair, R., 1985; Park, K. W. \& Goins, R. E., 1994; Tahoun, M. K., \& Ali, H. A., 1981). 
CHAPTER 2

JOURNAL ARTICLE 


\author{
Authors Title Page \\ CHROMATOGRAPHIC QUANTIFICATION OF ELAIDIC \\ ACID IN LARD AND MEXICAN DISHES PREPARED WITH LARD
}

Ana G. Boardman, Panfilo S. Belo* , Miriam Saltmarch, and Lucy McProud Department of Nutrition and Food Science

San Jose State University

1 Washington Square

San Jose, CA 95192

* Address questions and comments to: Dr. Panfilo Belo,

Department of Nutrition and Food Science, San Jose State University,

I Washington square, San Jose, CA 95192-0058, 408-924-3108 


\begin{abstract}
Non hydrogenated lard sample obtained from a local Mexican grocery store, refried beans and beef tamale samples obtained from Bay Area grocery stores were analyzed for total trans-9-octadecenoic (elaidic acid) composition. High performance glass capillary gas liquid chromatography on a $30 \mathrm{~m} \mathrm{5 \%}$ crosslinked $\mathrm{Ph}$ Me silicone column was employed in the separation and quantification of the cis- and trans- octadecenoic fatty acids. Under operating conditions employed in this study, methyl esters of elaidic acid were separated from oleic acid without any other complementary technique. Total elaidic acid accounted for $0.02 \%, 0.23 \%$, and $0.506 \%$ of the total fatty acids present in lard, refried beans and beef tamale samples, respectively. Based on these values, the degree of isomerization (elaidic acid content relative to oleic acid content) was estimated to be $0.483 \mathrm{mg} / \mathrm{g}$ in lard, $3792 \mathrm{mg} / \mathrm{g}$ in refried beans, and $18.43 \mathrm{mg} / \mathrm{g}$ in beef tamale. On wet basis, the total elaidic acid content of lard, refried beans and beef tamale were 0.1857 $\mathrm{mg} / \mathrm{g}, 0.0215 \mathrm{mg} / \mathrm{g}$ and $0.5869 \mathrm{mg} / \mathrm{g}$, respectively.

The estimated intake of elaidic acid per serving per day was $82.7 \mathrm{mg}$ for beef tamale and $2.7 \mathrm{mg}$ for refried beans.
\end{abstract}




\section{INTRODUCTION}

Changes in the eating and dietary patterns of Americans, along with economic growth and diversification of the United States' food supply, have resulted in the increased consumption of a variety of foods from different countries. Along with these changes in eating patterns and the relatively sudden abundance of different types of foods, there have been adverse changes in the health of the American population.

As little as 50 years ago, most Americans did not think of foods in terms of their effects on health. Today, as Americans gain weight and as their health declines, more and more scrutiny is being directed at the foods that they eat. Thanks to the miracles of modern science, the terms "fat-free" and "cholesterol-free" are now part of the every-day lexicon in American society. Today, education about the health benefits and hazards of different types of foods are prominently advertised and displayed by governmental associations and commercial industry.

From the vast variety of foods found in the U.S., one of the most commonly consumed by the general population, and especially by the Mexican-American population, is Mexican food. Mexican foods can now be found in almost every supermarket in the United States. Consequently, it comes as no surprise that Mexican foods, traditionally made with lard as a source of fat, are currently under fire. Specifically, ruminant depot animal fats have been targeted because of their low level of insaturation and by the presence of small amounts of trans fatty acids resulting from rumen biohydrogenation.

The shift from animal fats to vegetable fats has been encouraged in recent years, with the intention of increasing the levels of dietary polyunsaturated fatty acids (1). However, the resulting alterations are more complex than may be recognized, as the majority of vegetable fats consumed by Americans are modified chemically by partial hydrogenation procedures designed to prevent deterioration and convert the original oils 
to products with economically desirable physical properties (1). This produces a large number of positional and geometric isomers of 18:1 and 18:2 trans. Consequently, the fatty acid composition of the processed foods is different from that listed in handbooks for the original oils and animal fats. In addition trans fatty acids are easily made from the more readily available cis acids by stereomutation and there is evidence that this occurs inadvertently during processing at high temperatures.

Metabolic research on $\mathrm{C}_{18}$ trans monoenoic fatty acids has confirmed that as the percentage of this $\left(\mathrm{C}_{18}\right)$ dietary energy increases, there is a tendency for blood concentration of low density(LDL) cholesterol and lipoprotein $(a)\left(L p_{a}\right)$ to rise and for high density lipoprotein(HDL) cholesterol to fall (2). However, only a few epidemiological studies' results agreed with the results from these metabolic studies, and found a positive association between the consumption of trans fatty acids and coronary heart disease risk.

According to Wolff (3), experimental studies performed using animals as subjects have not found any association between trans fatty acids and any major adverse effects on health. In contrast, studies using human volunteers as subjects have shown that partially hydrogenated vegetable oils and fats produced a significant rise in serum cholesterol and LDL cholesterol, while reducing HDL cholesterol, than did cis-unsaturated acidcontaining diets.

Data from human and animal studies have shown that trans fatty acids' isomers from partially hydrogenated oils and fats are absorbed and incorporated into all organs and tissues. Data from tissue composition, as well as data from isolated enzyme studies and isotope tracer experiments with whole organisms, showed without a doubt that structural differences between the different fatty acid isomers influenced specific biochemical transformations. Differences in reaction rates and/or specificity of acyl transferase, lipase, 
desaturase and cholesteryl esterase/hydrolase were some of the effects of the various positional fatty acid isomers (4).

Currently fats and oils composition handbooks do not include information on trans' content, probably due to the unavailability of reliable data. This lack of reliable data is the direct cause of the absence of a simple procedure to determine small amounts of trans fatty acids in foods (5). Although many separation methods for geometric and positional isomers have been reported, there is a gap in the knowledge about how to separate and quantify positional and geometrical isomers using a simple and reliable method.

The fatty acid content in fats, oils, and foods is usually determined by means of gas liquid chromatography (GLC) of the fat's or oils' fatty acid methyl esters. With the development of glass capillary gas liquid chromatography, it is now possible to obtain information on the trans fatty acids' composition of foods (1). According to Lanza and Slover (5), current advances in technology on coated glass capillary columns have shown that glass capillary columns are the tools of choice for separating and quantifying individual fatty acid isomers.

Understanding of the recent developments in tools such as the capillary column to help in the determination and quantification of fatty acid isomers in foods and knowledge of the health effects of these isomers on humans, have resulted in the analysis of many foods and the determination of their trans fatty acid contents. Despite the incredible variety of foods analyzed, Mexican foods and non hydrogenated lard have largely been ignored. This is surprising considering that there is an ever-growing population of Mexican-Americans in the United States and that Mexican foods are becoming part of the mainstream, "American," diet. Given that Mexican foods continue to grow in availability and popularity in the United States, the trans fatty acid contents of Mexican foods should be examined. In the present paper, we evaluate the amount of individual cis and trans-9- 
octadecenoic acid in a non hydrogenated lard sample, as well as in two different traditional Mexican foods prepared with lard as a source of fat.

\section{MATERIALS AND METHODS}

\section{Chemicals}

Solvents of at least HPLC grade purity were obtained from Sigma Chemical Company as well as from Van Waters and Rogers, Inc., (VWR) (USA). Reference methyl esters, oleic acid methyl ester and elaidic acid methyl ester (purity 99\%) were from Sigma Chemical Company (USA). Other chemicals used were of analytical reagent grade and obtained either from Sigma Chemical Company or from VWR (USA). Samples

Lard sample. The non hydrogenated lard sample used in this study was obtained from a local Mexican grocery store. Refried beans and beef tamale samples were obtained from local grocery stores in the San Jose, California area.

Sample Preparation

Lard, refried beans' ant beef tamale samples were freeze dried in a Labconco Freeze Dry/Shell Freeze System (Lyph-Lock6) for 2 days. Drying was performed with the purpose of facilitating solvent penetration. Dried samples were stored frozen $\left(-20^{\circ} \mathrm{C}\right)$. Lipid Extraction

A volume of 1:1 hexane-ethyl ether ca. 20 times the sample weight was added to the weighted sample. The sample-solvent mixture was homogenized for 2 minutes in a modified tissue homogenizer and then filtered. The solvent was removed under vacuum with a rotary evaporator. Lipids extracted were stored frozen $\left(-20^{\circ} \mathrm{C}\right)$. Preparation of free fatty acids

Free fatty acids were prepared by heating $10 \mathrm{~g}$ of the lipids extracted in $100 \mathrm{ml}$ of $2.5 \%$ potassium hydroxide in ethanol under reflux conditions. After heating for $2 \mathrm{hr}$, the 
solution was acidified to $\mathrm{pH} 2$ with cold $1 \% \mathrm{H}_{2} \mathrm{SO}_{4}$ in water $(v / v)$. The free fatty acids were extracted using 3- to $100-\mathrm{ml}$ portions of hexane-ethyl ether (50:50). The organic extract was washed with water, dried over sodium sulfate and the solvent removed under vacuum with a rotary evaporator. Free fatty acids were also kept under freezing temperatures until they were methylated.

Methylation

Methyl esters were prepared from fatty acids using boron trifluoride-methanol according to AOAC Method 41.1.28 (6). Prepared methyl esters were frozen (-20\% $\mathrm{C})$ and kept at that temperature until its chromatographic analysis.

Gas liquid chromatography

Analytical gas liquid chromatography (GLC) of fatty acid methyl esters (FAME) of each sample was carried out with a Hewlett Packard 5890 gas chromatograph fitted with a flame ionization detector (FID) and Hewlett Packard 3365 series II integrator. The column used was a high performance capillary column coated with crosslinked $5 \% \mathrm{Ph} \mathrm{Me}$ silicone (HP-5 19091 J-413, 30m X $0.32 \mathrm{~mm}$ internal diameter; $0.25 \mu \mathrm{m}$ film thickness; Hewlett Packard). The gas Chromatographic conditions were a spilt mode inlet system at 400.5/0.5 split ratio, helium as carrier gas at $0.5 \mathrm{ml} / \mathrm{min}$ linear gas rate, nitrogen as an auxiliary gas at a flow rate of $34.5 \mathrm{ml} / \mathrm{min}$; hydrogen flow rate was $30 \mathrm{ml} / \mathrm{min}$; and compressed air was $400 \mathrm{ml} / \mathrm{min}$. Injector temperature was $220^{\circ} \mathrm{C}$, detector temperature was $275^{\circ} \mathrm{C}$. The column was operated isothermally at $150^{\circ} \mathrm{C}$ for 1 minute, temperature was then increased at a rate of $10^{\circ} \mathrm{C} / \mathrm{min}$ up to $207^{\circ} \mathrm{C}$ and held at this temperature for 1 minute, a second temperature increase was performed at a rate of $0.1^{\circ} \mathrm{C} / \mathrm{min}$ up to 209 ${ }^{\circ} \mathrm{C}$ and held at that temperature for another minute. The temperature was again increased at a rate of $2^{\circ} \mathrm{C} / \mathrm{min}$ up $250^{\circ} \mathrm{C}$ and held finally at this temperature for 5 minutes. (See 
figure 3). Aliquots of 0.6 microliters of the sample methyl esters were manually injected into the apparatus.

Figure 3. Chromatographer Oven

Temperature Programming

Initial oven temperature $150{ }^{\circ} \mathrm{C}$

rate 1: $10^{\circ} \mathrm{C} / \mathrm{min}$ until oven temp $207^{\circ} \mathrm{C}$, time at $207^{\circ} \mathrm{C}: 1 \mathrm{~min}$ rate 2: $0.1{ }^{\circ} \mathrm{C} / \mathrm{min}$ until oven temperature $209^{\circ} \mathrm{C}$, time at $209^{\circ} \mathrm{C}$ : $1 \mathrm{~min}$ rate 3: $2{ }^{\circ} \mathrm{C} / \mathrm{min}$ until oven temperature $250^{\circ} \mathrm{C}$, time at $250{ }^{\circ} \mathrm{C}$ : $1 \mathrm{~min}$

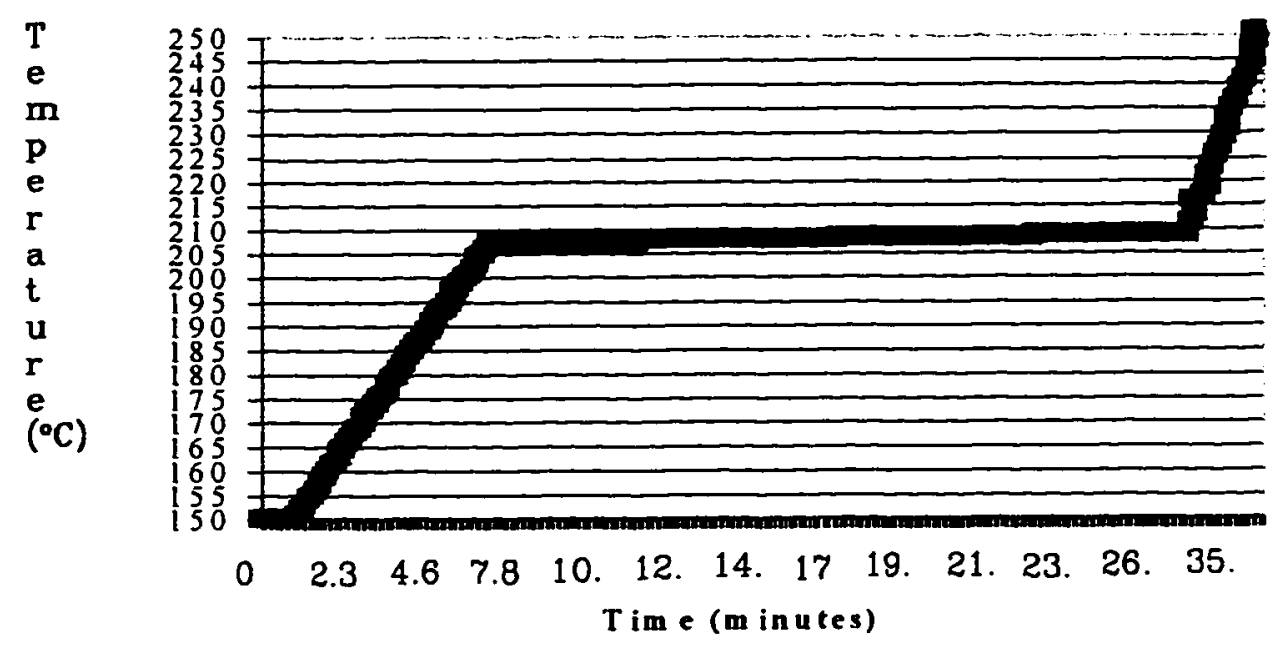

Peaks were identified by comparison with authentic standards and quantitative analysis was performed by using a Hewlett Packard ChemStation (MS-DOS series) version A.03.34 Software.

\section{RESULTS AND DISCUSSION}

Sample Preparation

Samples were thoroughly dried to facilitate solvent penetration as well as eliminate water interference in the subsequent reactions of this sample preparation for chromatographic analysis (7). Freeze drying of samples was the method of choice for its advantages over other methods; principally, because, this method uses low temperatures to evaporate the water in the food. As a result, unsaturated and saturated lipids present in 
the samples were less likely to undergo deterioration reactions. Moisture values for the three samples analyzed are shown in table 4.

\section{Lipid Extraction}

The extraction method used was selected as the method of choice from recent comparison studies of various methods for total lipid extraction $(8,9,10)$. Reproducibility and effectiveness were obtained by using a hexane-ethyl ether extraction system. When choosing the solvent mixture, potential hazards and effectiveness of the solvent were taken into consideration. (9). Based on literature reviewed, we found, that with this solvent mixture, non polar as well as polar lipids were extracted efficiently. After extraction, the solvent and other volatile substances in the extract mixture were evaporated by using a rotary evaporator under vacuum. This method of evaporation offered advantages over other methods because it decreases the possibility of deterioration of the fat extracted. Values for total fat in dry basis (table 4) vary very little among samples: beef tamale with overall mean value of $27.75 \%$, refried beans with overall mean value of $5.97 \%$, and non hydrogenated lard with overall mean value of $99.06 \%$.

Preparation of free fatty acids

According to many research studies, it is not absolutely necessary to hydrolyze triglycerides to free fatty acids before methylation because most lipids can be transmethylated directly. However, methylation reaction rates are faster when triglycerides undergo alkaline hydrolysis, and the reason is simple. Free fatty acids released, from the lipid hydrolysis, are more soluble in methanol than triglycerides, understanding that methanol is the solvent system used in the methylation reaction (11). Then, they can then be esterified with an acid reagent like boron fluoride alcoholate at a faster rate. Alkalicatalyzed hydrolysis is usually carried out by refluxing extracted lipids with $0.5 \mathrm{~N}$ $\mathrm{KOH} / \mathrm{MeOH}$. However, triglycerides have a poor solubility in methanol which is the 
reason for which in our procedure we used a $2 \% \mathrm{KOH} / \mathrm{EtOH}$. Even though the reaction rate was slow, we were assured that a complete lipid hydrolysis occurred, since alkaline hydrolysis of triglycerides is essentially irreversible. The free fatty acids obtained from this reaction were well dissolved in methanol. Solvent system used in the following reaction of our procedure. As a result, fatty acid methyl ester formation was facilitated. Methylation

Boron trifluoride alcoholate is commonly used for esterifying carboxylic acids. $\mathrm{BF}_{3} / \mathrm{MeOH}$ compared with other acidic catalysts has a higher esterifying than transesterifying capabilities. Methylation of free fatty acids using this strong Lewis acid is faster as took 2 minutes, and a qualitative and quantitative methylation of free fatty acids was ensured. This process was replicated 3 times in order to ensure reliability of results. However, water must be eliminated from the system, since it can reverse the esterification reaction products (11).

Gas liquid chromatography

Under the conditions used in these analyses, the high performance capillary column coated with crosslinked 5\% Ph Me silicone (HP-5 19091J-413, 30m X $0.32 \mathrm{~mm}$ internal diameter; $0.25 \mu \mathrm{m}$ film thickness), gave excellent qualitative separation of a mixture of pure standards of 9-trans and 9-cis-18:1 isomers. The gas chromatogram for 9-cis and 9trans-octadecenoic fatty acids (oleic and elaidic acid respectively) is shown in figure 4. Baseline separation was achieved by direct GLC.

The content of 9-cis and 9-trans octadecenoic acids in lard, beef tamale and refried beans was measured. Analyses were carried out in triplicates. The oleic and elaidic acids' composition of the three samples was determined by this chromatographic method, and results are listed in table 4. Cis-9-18:1 eluted before trans-9-octadecenoate. Known standards were used to identify the peaks and a computing integrator was used to quantify 
the data produced. The range of trans fatty acids in these samples was from 0.02 to $0.51 \%$ of total fatty acids. The highest value was found in beef tamale.

Figure 5 is a chromatogram obtained for fatty acid methyl esters (FAME) of non hydrogenated lard, figure 6 is the chromatogram obtained for FAME of beef tamale, and figure 7 is the chromatogram obtained for FAME of refried beans. Peaks of interest were identified by comparison of the retention time of the unknown peak in the chromatogram with that of oleic and elaidic standard peaks in another chromatogram, because this is the simplest method of identification. Based on figures 5, 6 and 7, the fatty acid profile for the three samples is similar for the three samples indicating that the three samples were prepared using the same kind of fat source: lard. Quantitative analysis indicated differences in amounts of those fatty acids for each sample. Only oleic and elaidic acid amounts were determined in this study.

The official method of analysis of trans fatty acids by the Association of Analytical Chemists uses a polar stationary phase. Separation of components by using this phase is based on the dipole interaction between the phase and the components being analyzed. However, in this study a non polar stationary phase in which separation in base in the different boiling points of the components being analyzed was used. The isomers analyzed, cis-9-18: 1 and trans-9-18:1, have very close boiling points 286 and 288 at 100 psi of pressure respectively. Separation between the two isomers analyzed was achieved. However, time of analysis was long, 50.2 minutes per run. According to Litchfield, et al. (12), this kind of non polar stationary phases (methyl silicone stationary phases) were generally believed to be useful only for separating compounds of different molecular weights. However, the presence of the hydroxyl or keto group in these methyl silicone compounds may aid in the separation of geometrical isomers that have the same molecular weight. Poly 50\%-methyl/5\%-phenylsilaxone phases are found at the present time to be 
the second most popular of the silaxone liquid phases. Usually these stationary phases were generally recommended for the analysis of aromatic and heteroaromatic compounds, drugs steroids, and trimethylsilyl derivatives (13). However, this research found that these phases have a use in the determination of trans unsaturation of fats in biological materials. Nevertheless, in this study no overlaps in the cis-9-18:1 area by other cis- $n-18: 1$ isomers were determined, nor were these overlaps in the trans-9-18:1 area by other trans$\mathrm{n}-18: 1$ isomers. As a consequence, this study cannot assure that the stationary phase used is able to separate more isomers than the analyzed. The possibility of having overlaps in the same area of the compounds analyzed exists.

Edwards, et al. (14) discovered that in gas chromatographic analysis, the retention time of the components being analyzed decreased as the duration of column use increased. During the course of this study, this was found to be true. In order to minimize the possible errors that could be caused by the variation in retention times of the sample components, each sample was analyzed the same day. Experimental conditions were identical and the chromatograms were obtained from consecutive runs. Although the quantitative analysis of food lipids relies heavily on the accurate setting up and calibration of instrumentation, excellent results can be obtained from GLC techniques.

In the chromatographic analysis, injection split mode was used instead of diluting the sample methyl esters before injection into the apparatus. Results indicated that when using this split mode and flows of carrier gas were set manually variations on the sample entering the column may occur, as happened in this research. However, we overcame that problem by using corrections factors. Quantitative data could then be obtained after making the necessary tabulations.

Elaidic acid consumption estimations based on the data obtained and on the amount per servings given in product nutritional information were calculated. The 
estimated intake of elaidic acid per serving per day was $82.7 \mathrm{mg}$ for the beef tamale and $2.7 \mathrm{mg}$ for the refried beans samples. No estimation was calculated for the lard sample because of the lack of information on the size serving. This suggests that the two samples of traditional Mexican dishes analyzed contribute considerable amounts of elaidic acid to the human diet.

Table 4. Moisture, fat, oleic and elaidic acid content of lard, refried beans and beef tamale samples.

\begin{tabular}{|l|c|c|c|}
\hline Sample & Lard & $\begin{array}{c}\text { Refried } \\
\text { Beans }\end{array}$ & Beef Tamale \\
\hline Moisture (\% wet basis) & $0.62 \pm 0.01$ & $74.9 \pm 1.00$ & $57.05 \pm 0.5$ \\
\hline Total Fat (\% wet basis) & $98.4 \pm 0.03$ & $1.5 \pm 0.05$ & $11.91 \pm 0.19$ \\
\hline Total Fat (\% dry basis) & $99.0 \pm 0.05$ & $6.0 \pm 0.35$ & $27.75 \pm 0.4$ \\
\hline $\begin{array}{c}\text { Oleic Acid } \\
\text { (\% of total fatty acids) }\end{array}$ & $41.7 \pm 2.67$ & $59.6 \pm 1.78$ & $27.46 \pm 0.54$ \\
\hline $\begin{array}{c}\text { Elaidic Acid } \\
\text { (\% of total fatty acids) }\end{array}$ & $0.02 \pm 0.001$ & $0.23 \pm 0.014$ & $0.51 \pm 0.015$ \\
\hline
\end{tabular}

$\mathrm{n}=3$ 
$18: 1$

$\mathbf{t}$

$\mathbf{R}$

e

$s$

$\mathbf{P}$

(

n

$\mathbf{s}$

e
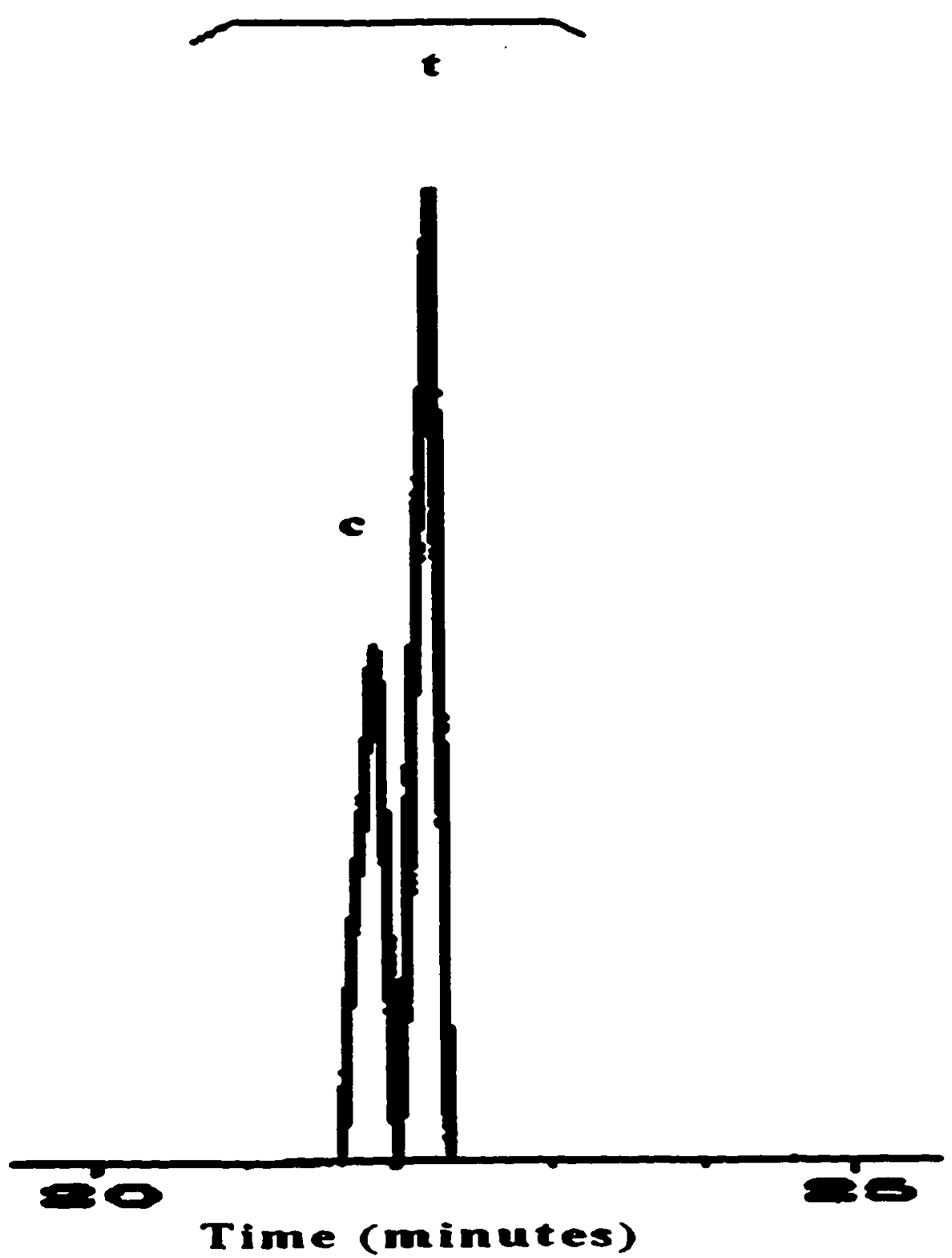

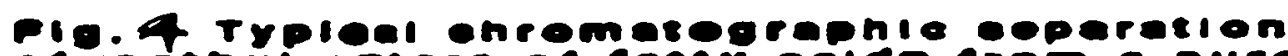

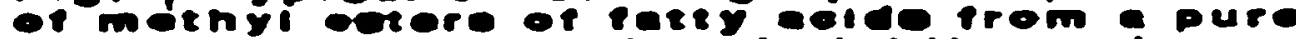

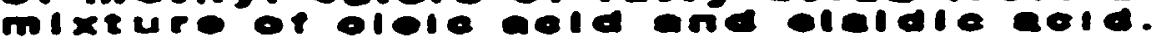




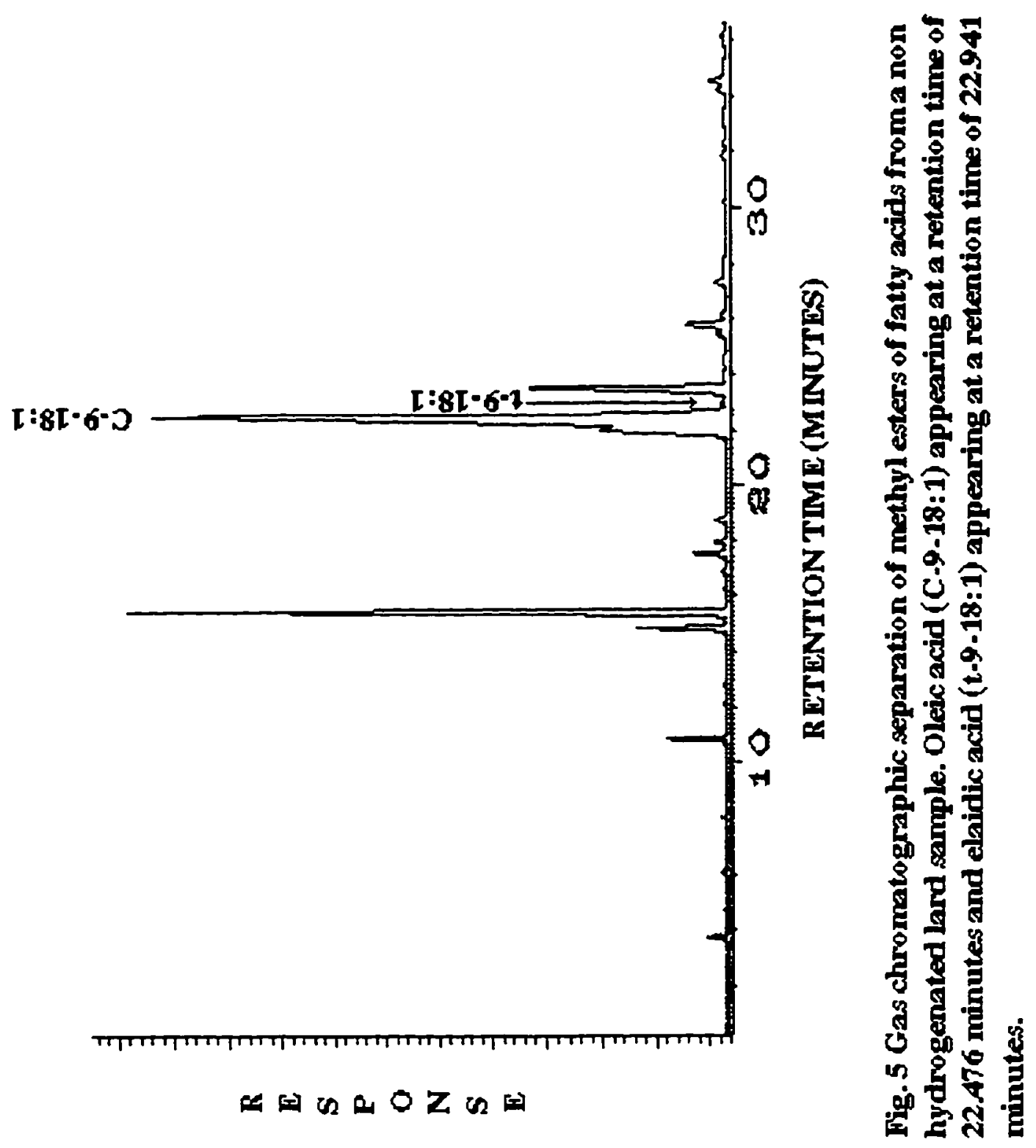




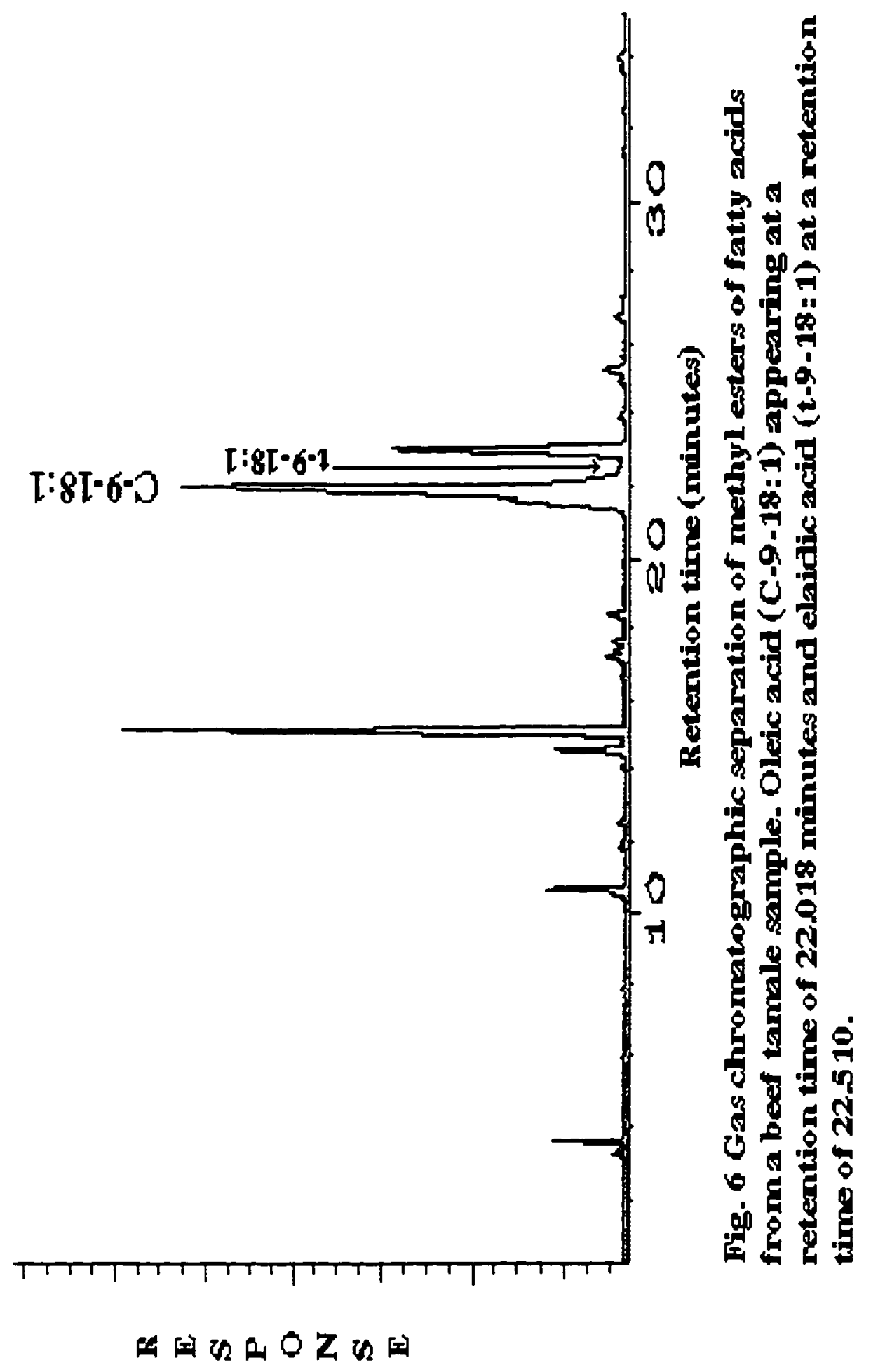




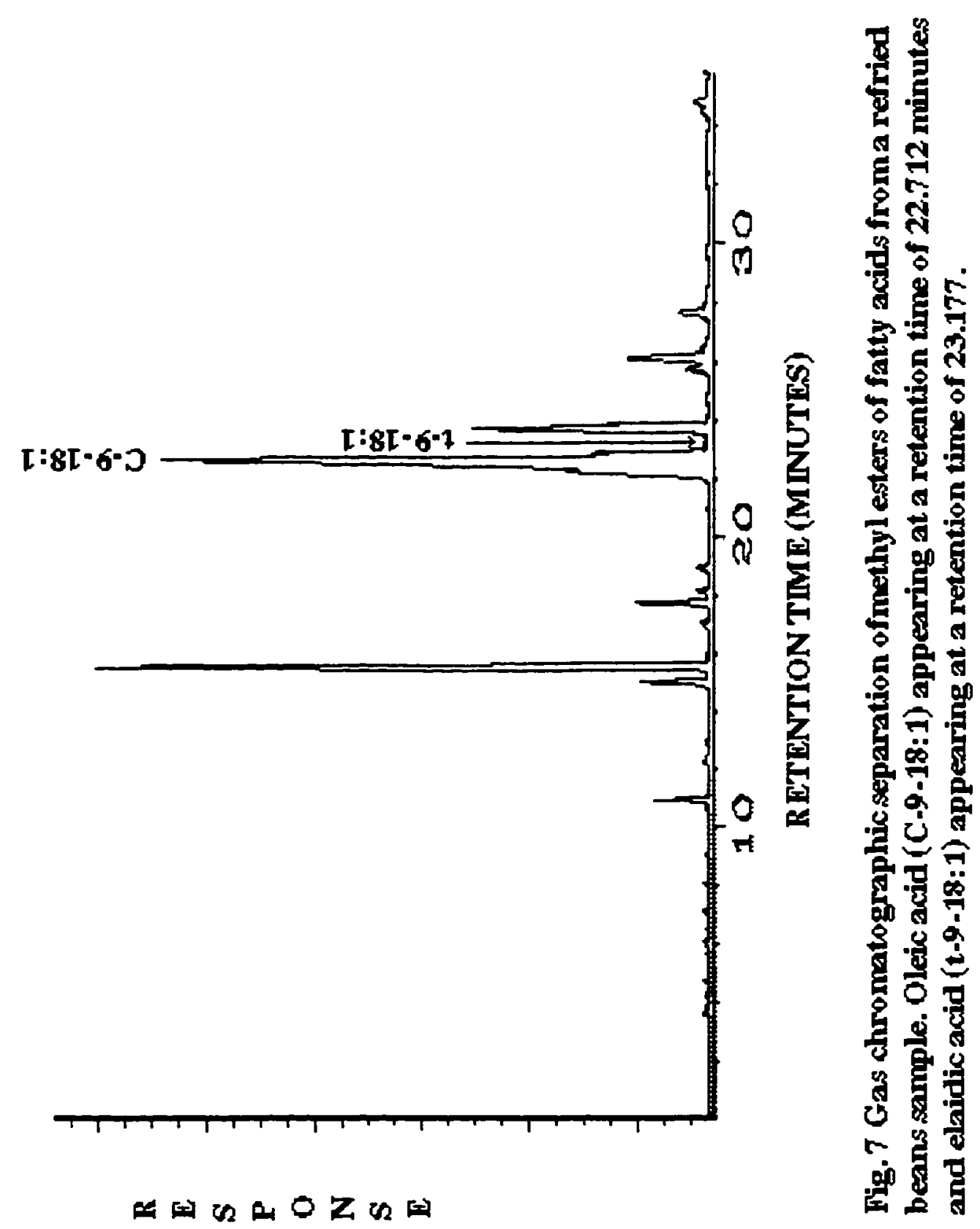


ACKNOWLEDGMENTS. This work was supported in part by San Jose State University, Department of Nutrition and Food Science, San Jose, CA.

\section{LITERATURE CITED}

1. Enig, M. G., Palansch, L. A., Sampugna, J., and Keeney, M., J. Am. Oil Chem. Soc. $60: 1788$ (1983).

2. Gurr, M., Lipid Technology 9:111 (1995).

3. Wolff, R. L., J. Am. Oil Chem. Soc. 71:277 (1994).

4. Emken, E. A., Ibid 60:995 (1983).

5.Lanza, E., and Slover, H. T., Lipids. 16:260 (1981).

6. Official Methods of Analysis, Association of Official Analytical Chemists, 16 edn., Washigton, D.C., 1995, Method 41.1.28.

7. Park, P.W. \& Goins, R. E., Journal of Food Science. 59: 1262 (1994).

8. Ganzler, K., Salgo, A., \& Valko, K., Journal of Chromatography. $371: 299$ (1986).

9. Chen, S., Shen, C.-S.J., \& Sheppard, A.J., J. Am. Oil Chem Soc. May: 599 (1981).

10. Sahasrabudhe, R \& Smallbone, B.W., Ibid. 60:801 (1983).

11. Liu, K., Ibid. 71:1179 (1994).

12. Litchfield, C., Reiser, R, \& Isbell, A. F., Ibid. 40:302 (1963).

13. Yancey, J.A., Journal of Chromatographic Science. 24: 117 (1986).

14. Edwards, H.M., \& Marion, J.D., J. Am. Oil Chem Soc. 40:299 (1963). 


\section{CHAPTER 3}

\section{SUMMARY AND RECOMMENDATIONS}

\section{Summary}

Non hydrogenated lard, refried beans, and beef tamale samples were analyzed to determine their total trans-9-octadecenoic (elaidic acid) composition. Non- hydrogenated lard, refried beans, and beef tamale contained $99.06,5.97$ and $28.27 \%$ fat. All values were computed on dry basis.

Preliminary study of hydrolysis and methylation of the fat extracted from the samples revealed that the methods used were efficient and yielded the same amounts of fatty acids and fatty acid methyl esters every time the samples were subjected to these treatments. Preliminary study of the separation between cis-9-octadecenoic (oleic acid methyl ester) and trans-9-octadecenoic (elaidic acid methyl ester) methyl esters from a pure standard mixture of the two isomers was performed using a Hewlett Packard (HP) 5890 gas chromatograph. The chromatograph was fitted with a flame ionization detector (FID) and HP 3365 series II integrator. The column used for this analysis was a $30 \mathrm{~m}$ high performance capillary column coated with crosslinked 5\% $\mathrm{Ph}$ Me silicone (HP-5 $19091 \mathrm{~J}-413,0.32 \mathrm{~mm}$ internal diameter; $0.25 \mu \mathrm{m}$ film thickness; HP). Different condition chromatographic conditions were tested. Results revealed that the best chromatographic conditions to achieve detection and separation of the two isomers were the following: A spilt mode inlet system at $400.5 / 0.5$ split ratio, helium as carrier gas at $0.5 \mathrm{ml} / \mathrm{min}$ linear gas rate, nitrogen as an auxiliary gas at a flow rate of $34.5 \mathrm{ml} / \mathrm{min}$; hydrogen flow rate was $30 \mathrm{ml} / \mathrm{min}$; and compressed air was $400 \mathrm{ml} / \mathrm{min}$. The injector and detector temperatures were $220^{\circ} \mathrm{C}$ and $275^{\circ} \mathrm{C}$, respectively. The column was operated isothermally at $150^{\circ} \mathrm{C}$ for 1 minute, temperature was then increased at a rate of $10^{\circ} \mathrm{C} / \mathrm{min}$ up to $207^{\circ} \mathrm{C}$ and held at this temperature for 1 minute, a second temperature increase was performed at a rate of 
$0.1^{\circ} \mathrm{C} / \mathrm{min}$ up to $209^{\circ} \mathrm{C}$ and held at that temperature for another minute. The temperature was again increased at a rate of $2^{\circ} \mathrm{C} / \mathrm{min}$ up $250^{\circ} \mathrm{C}$ and held finally at this temperature for 5 minutes.

Qualitative and quantitative determination of the oleic and elaidic acid isomers were performed by manually injecting aliquots of $0.6 \mu \mathrm{l}$ of the sample methyl esters into the gas chromatograph. Peaks were identified by comparison with authentic standards and quantitated analysis was performed.

On a dry-weight basis, elaidic acid content for non hydrogenated lard, refried beans, and beef tamale was $0.0201,0.226$, and $0.506 \%$ of total fatty acids for each sample respectively. On a wet-weight basis, elaidic acid content for the three samples was $0.186,0.0214$, and $0.587 \mathrm{mg}$ per gram of sample.

Serving per size of beef tamale was 1 tamale (14lg) and serving per size of refried beans was $1 / 2$ cup ( $128 \mathrm{~g}$ ). Estimations of the intake of elaidic acid per serving per day were made. Results indicated a consumption of elaidic acid per serving size per day of $82.7 \mathrm{mg}$ for beef tamale and $2.7 \mathrm{mg}$ for refried beans.

\section{Recommendations}

Although the elaidic acid content of the three Mexican samples analyzed (non hydrogenated lard, refried beans and beef tamale) were in the micrograms range, its effects on human health should still be considered. Like any other quantitative analysis, researchers should be careful and accurate in preparing and analyzing samples, especially when analyzing trans fatty acids since the trans-9-octadecenoic acid content is usually in the microgram scale. A quantitative extraction of fat from the sample and transformation of lipids to fatty acid methyl esters should be assured.

Chromatographic techniques for the analysis of fatty acids require a knowledgeable analyst who can encounter and solve the many problems that these techniques may 
involve. When using split mode manually set, care should be taken because it is difficult to manually control the flow of the carrier gas. In this case, this mode is absolutely necessary for the analysis. Determination and use of correction factors is recommended in order to assure reliable results.

During the course of this study, it was noticed that retention times of the two isomers analyzed (oleic and elaidic acid methyl esters) decreased each run. Analysts need to take into account that the life of the column decreases with each analysis, and thereby affects the retention time of the compounds being analyzed. Calibration of the chromatographer should be performed every other unknown sample (Example: calibration-sample, calibration-sample, and so on). Overestimation of either trans-9octadecenoic acid or cis-9-octadecenoic acid may have occurred during this analysis due to overlaps of other 9-octadecenoic acid isomers in the area in which elaidic and oleic acid methyl esters appeared in the study.

In future studies of the analysis of trans fatty acids in foods, the overlaps of other isomers, preparation of samples for chromatographic analysis, and length of analysis time should be taken into consideration. Modification of the methodology of sample preparation for this analysis (specifically, combining the hydrolysis and methylation of fatty acids into one process), could significantly decrease time required for this transformation and decrease the potential of sample loss. However, complete transfer of total fatty acids present in the extracted fat from the food should be assured. In addition, manipulation of chromatographic analysis conditions could result in a decrease in time needed for analysis. 


\section{References}

Aro, A., Kardinall, A. F. M., Salminen, I., Kark, J. D., Riemersma, R. A., Delgado-Rodriguez, M., Gomez-Aracena, J., Huttenen, J. K., Kohlmeier, L., Martin, B. C., Martin-Moreno, J. M., Mazaev, V. P., ringstad, J., Thamm, M., van't Veer, P., \& Kok, F. J. (1995). Adipose tissue isomeric trans fatty acids and risk of myocardial infarction in nine countries: the EURAMIC study. The Lancet, 345, 273-277.

Brisson, G. J. (1981). Dietary fats and body lipids: terms used. Lipids in Human Nutrition (pp. 1). Englewood, NJ: Jack K. Burgess, Inc.

Chen, S., Shen, C.-S. J., \& Sheppard, A. J. (1981). Comparison of methylene chloride and chloroform for the extraction of fats from food products. Journal of the American oil chemists' society, 599-601.

Christie, W. W. (1982). The structure, Chemistry and occurrence of lipids. Lipid Analysis. New York: Pergamon Press.

Christie, W. W. (1995). Are methyl esters of fatty acids the best choice for gas chromatographic analysis. Lipid Technology 64-66.

Christie, W. W., Breckenridge, G. H. McG. (1989). Separation of cis and trans isomers of unsaturated fatty acids by high-performance liquid chromatography in the silver ion mode. Journal of Chromatography, 469, 261-269.

Condon, R., \& Condon, W. (1988). !Ole Mole! Great Recipes in the Classic Mexican Tradition. Dallas, Tx: Taylor Publishing Company.

Craig-Schmidt, M. C. (1992). Fatty acid isomers in foods. In Chow, C. K. (Ed.) Fatty acids in foods and their health implications (pp. 365-398). New York: Marcel Dekker, Inc.

Decsi, T., \& Koletzko, B. (1995). Do trans fatty acids impair linoleic acid metabolism in children?. Annals of Nutrition Metabolism, 39, 36-41. 
deMan, L., \& deMan, J. M. (1983). Percent trans fatty acids in milk fat. Journal of the American Oil Chemists' Society, 60, 1095-1098.

Desmedt, A., Culot, C., Deroanne, C., Durant, F., \& Gibon, V. (1990). Influence of cis and trans double bonds on the thermal and structural properties of monoacid triglycerides. Journal of the American Oil Chemists' Society, 67, 10, 653-660.

Emken, E. A. (1983). Biochemistry of unsaturated fatty acid isomers. Journal of the American Oil Chemists' Society, 60, 5, 995-1004.

Enig, M. G., Atal, S., Keeney, M., \& Sampugna, J. (1990). Isomeric trans fatty acids in the U.S. diet. Journal of the American College of Nutrition, 9, 5, 47-486.

Enig, M. G., Palansch, L. A., Sampugna, J., \& Keeney, M. (1983). Fatty acid composition of the fat in selected food items with emphasis on trans components. Journal of the American Oil Chemists' Society, 60, 10, 1788-1795.

Folch, J., Lees, M., \& Sloane-Stanley, G. H. (1957). A simple method for the isolation and purification of total lipides from animal tissues. Journal biological chemistry, 226, 497-509.

Giese, J. (1996). Fats and fat replacers: Balancing the health benefits. Food Technology, 50, 9, 76-78.

Gunstone, F. D., Harwood, J. L., \& Padley, F. B. (1986). The Lipid Handbook. New York: Chapman and Hall.

Gurr, M. (1992). Role of fats in food and nutrition (p.45). New York: Elsevier Applied Science.

Hammond, E. W. (1981). Quantitative chromatographic analysis in foods. Chromatography, 13, 117, 397-403.

Holley, K. M., \& Phillips, P. S. (1995). Trans-fatty acids: and introduction. Nutrition \& Food Science, 2, 31-33. 
Jennings, W. (1978). Gas Chromatography with Glass Capillary Columns (pp. 1920). New York: Academic Press.

Karin, M., \& Sacks, F. (1995). Trans fatty acids in European Margarines. New England Journal of Medicine, 332, 8, 541-542.

Katan, M. B., Zock, P. L., \& Mensink, R. (1994). Effects of fats and fatty acids on blood lipids in humans: an overview. American Journal of Clinical Nutrition, 60(suppl), 1017S-1022S.

Kennedy, D. (1978). Recipes from the Regional Cooks of Mexico. New York: Harper \& Row, Publishers.

Koletzko, B. (1992). Trans fatty acids may impair biosynthesis of long-chain polyunsaturates and growth in man. Acta-Paediatrica, 81, 4, 302-306.

Litchfield, C., Reiser, R., \& Isbell, A. F. (1963). The analysis of cis-trans acid isomers using gas-liquid chromatography. Journal of the American oil chemists' society, 40, 302-308.

Liu, K. (1994). Preparation of fatty acid methyl esters for gas-chromatographic analysis of lipids in biological materials. Journal of the American oil chemists' society, 71 , $11,1179-1187$.

Mensink, R. P., de Louw, M. H. J., \& Katan, M. B. (1991). Effects of dietary trans fatty acids on blood pressure in normotensive subjects. European Journal of Clinical Nutrition, 45, 375-382.

Misir, R., Laarveld, B., \& Blair, R. (1985). Evaluation of a rapid method for preparation of fatty acid methyl esters for analysis by gas-liquid chromatography. Journal of Chromatography, 331, 141-148.

Murkherjee, K. D., \& Weber, N. (1993). In Sherma, J. (Ed.), CRC handbook of chromatography: Analysis of lipids. (pp. 140-141, 376). Boca Raton, Fl: CRC Press. 
Musgrove, S. (1988). Separating cis and trans isomers of margarine fats by GC. Laboratory Practices, $37,12,40$.

Park, P. W., \& Goins, R. E. (1994). In situ preparation of fatty acid methyl esters for analysis of fatty acid composition in foods. Journal of Food Science, 59, 6, 12621266.

Parodi, P. W., \& Dunstan, R. J. (1971). The trans unsaturation content of Queensland milk fats, Aust. Journal of Dairy Technology, 26, 60-62.

Peyton, J. W. (1995). El Norte: The cuisine of northern Mexico (pp. 1-16). Santa Fe, New Mexico: Red Crane Books.

Piotrowski, J. (1995). In Greeley, A. (Ed.), Mexico: Experience the cuisine and music of Mexico (pp.5-7). New York: Macmillan.

Poole, C. F., \& Shuette, A. S. (1984). Contemporary practice of chromatography (pp. 29-121). New York: Elsevier.

Ratnayake, W. M. N., \& Beare-Rogers, J. L. (1990). Problems of analyzing $C_{18}$ cis and trans-fatty acids of margarine on the SP-2340 capillary column. Joumal of Chromatographic Science, 28, 633-639.

Roberts, T. L., Wood, D. A. Riemersma, R. A., Gallagher, P. J. \& Lampe, F. C. (1995). Trans isomers of oleic and linoleic acids in adipose tissue and sudden cardiac death. Lancet, 345, 278-282.

Sahasrabudhe, R., \& Smallbone, B. W. (1983). Comparative evaluation of solvent extraction methods for the determination of neutral and polar lipids in beef. Journal of the American Oil Chemists' Society, 60, 4, 801-805.

Salter, A. M. (1995). The influence of trans-fatty acids on health. Comment. Clinical Science Colch, 88, 4, 373-374. 
Sammpugna, J., Pallansch, L. A., Enig, M. G., \& Keeney, M. (1982). Rapid analysis of trans fatty acids on SP-2340 glass capillary columns. Journal of Chromatography, 249, 245-255.

Smith , L. M., Clifford, A. J., Hamblin, C. L., \& Creveling, R. K. (1986). Changes in physical and chemical properties of shortenings used for commercial deep-frying. Journal of the American Oil Chemists' Society, 63, 1017-1023.

Smith, L. M., Dunkley, W. L., Franke, A., \& Dairiki, T. (1978). Measurement of trans and other isomeric unsaturated fatty acids in butter and margarine. Journal of the American Oils Chemists' Society, 55, 257-261.

Stender, S. J., Dyerberg, J., Holmer, G., Ovesen, L., \& Sandstrom, B. (1995). The influence of trans-fatty acids on health: A report from the Danish Nutrition Council. Clinical Science Colch, 88, 4, 375-392.

Taohun, M. K., \& Ali, H. A. (1981). A modified method preparation and GLC determination of methyl esters of fats at milligram scale. Milchwissenschaft, 36, 7, 419421.

Ulberth, F., \& Henninger, M. (1994). Quantification of trans fatty acids in milk fat using spectroscopic and chromatographic methods. Journal of Dairy Research, 61 , $517-527$.

Willet, W. C. \& Ascherio, A. (1994). Trans fatty acids: Are the effects only marginal. American Journal of Public Health, 84, 5, 722-724.

Willet, W. C., Stammpfer, M. J., Manson, J. E., Coditz, G. A., Speizer, F. E., Rosner, B. A., Sammpson, L. A., \& Hennekens, C. H. (1993). Intake of trans fatty acids and risk of coronary hearth disease among women. The Lancet, 341, 581-586.

Woodrow, I. L., \&\& de Man, J. M. (1968). Distribution of trans-unsaturated fatty acids in milk fat. Biochim. Biophys. Acta, 152, 472-478. 